\title{
La ciudad ibérica de Masies de Sant Miquel (Banyeres del Penedès, Tarragona) entre los siglos VII-III a. C. Resultados de una investigación con métodos no invasivos*
}

\section{The Iberian town of Masies de Sant Miquel (Banyeres del Penedès, Tarragona) between the $7^{\text {th }}-3^{\text {rd }}$ centuries BC. Results of an investigation with non-invasive methods}

\author{
Jaume Noguera ${ }^{1}$ \\ Joan Sanmartí ${ }^{2}$ \\ Universidad de Barcelona \\ Maria Carme Belarte ${ }^{3}$ \\ ICREA e ICAC \\ Roger Sala ${ }^{4}$ \\ SOT Archaeological Prospection \\ Jordi Morer ${ }^{5}$ \\ Món Iber ROCS SL \\ David Asensio ${ }^{6}$ \\ Eduard Ble ${ }^{7}$ \\ Rafel Jornet ${ }^{8}$ \\ Víctor Revilla ${ }^{9}$ \\ Universidad de Barcelona \\ Josep Pou $^{10}$ \\ Ayuntamiento de Calafell
}

\section{RESUMEN}

Se presentan los resultados históricos derivados de la primera fase de la investigación sobre este importante yacimiento, realizada exclusivamente a partir de métodos no invasivos. Los datos recuperados a partir de la prospección pedestre y geofísica han permitido verificar la condición urbana del asentamiento, atestiguada tanto por sus dimensiones como por su complejidad estructural y la naturaleza de los materiales muebles recuperados, que sugieren actividades económicas especializadas y la coexistencia de distintos sectores sociales. La desaparición del asentamiento en torno a 200 a. C. confirma

\footnotetext{
"Proyecto "Caracterización de los asentamientos urbanos en las áreas costeras de la Iberia septentrional (siglos VI-III a. C.)" (CAUCIS). Financiado por el Ministerio de Ciencia, Innovación y Universidades, HAR2015-67946-C2-1/2-P.

1 noguera@ub.edu / ORCID iD: http://orcid.org/0000-00015698-3606
}

el profundo impacto de la conquista romana en los patrones de poblamiento del mundo ibérico septentrional.

\section{SUMMARY}

We present the historical results derived from the first phase of research on this important site, conducted exclusively with non-invasive methods. The data recovered from pedestrian and geophysical prospecting have allowed us to verify the urban

\footnotetext{
${ }^{2}$ ORCID iD: http://orcid.org/0000-0002-6635-9249

3 ORCID iD: http://orcid.org/0000-0002-2293-0482

${ }^{4}$ ORCID iD: http://orcid.org/0000-0003-2886-5148

5 ORCID iD: http://orcid.org/0000-0003-4199-4358

${ }^{6}$ ORCID iD: http://orcid.org/0000-0003-3957-8435

${ }^{7}$ ORCID iD: http://orcid.org/0000-0002-2931-0454

${ }^{8}$ ORCID iD: http://orcid.org/0000-0002-7860-909X

${ }^{9}$ ORCID iD: http://orcid.org/0000-0002-2779-159X

${ }^{10}$ ORCID iD: http://orcid.org/0000-0001-8286-749X
} 
condition of the settlement, attested not only by its size, but also by its structural complexity and the nature of the pottery collected, which suggest specialized economic activities and the coexistence of different social sectors. The abandonment of the settlement around 200 BCE confirms the profound impact of the Roman conquest on the settlement patterns of the northern Iberian world.

PALABRAS CLAVE: cultura ibérica; urbanismo; arquitectura militar; organización social; conquista romana.

KEY WORDS: Iberian culture; urbanism; military architecture; social organization; Roman conquest.

CÓMO CITAR ESTE ARTÍCULO / CITATION: Noguera, J. Sanmartí, J., Belarte, M. C., Sala, R., Morer, J., Asensio, D., Ble, E., Jornet, R., Revilla, V. y Pou, J. 2020: "La ciudad ibérica de Masies de Sant Miquel (Banyeres del Penedès, Tarragona) entre los siglos VII-III a. C. Resultados de una investigación con métodos no invasivos", Archivo Español de Arqueología 93, 35-60. https://doi.org/10.3989/ aespa.093.020.002

\section{INTRODUCCIÓN}

En este artículo se presentan los resultados históricos obtenidos recientemente en el yacimiento ibérico de Masies de Sant Miquel y su entorno inmediato a partir del uso de métodos no invasivos, y se formula una síntesis interpretativa sobre este importante asentamiento. Las intervenciones se han limitado a distintas modalidades de prospección, tanto pedestre como geofísica (electromagnética, magnética y georradar); no han implicado remoción de tierras ni alteración del registro arqueológico, excepto la recogida controlada de material en superficie. Estos trabajos, realizados durante el año 2018, se integran en el proyecto de investigación CAUCIS, que pretende profundizar en el conocimiento del proceso de urbanización en época prerromana y su conexión con la formación de los estados ibéricos arcaicos. Otras intervenciones similares, pero acompañadas de trabajos de excavación, se han realizado en los yacimientos de Ullastret (Gerona), Burriac (Cabrera de Mar, Barcelona), Coll del Moro (Gandesa, Tarragona) y Vilar de Valls (Tarragona), siempre en el marco del mismo proyecto.

En un trabajo reciente (Belarte et alii 2019) hemos definido la ciudad como "un asentamiento densamente ocupado cuyo tamaño (no menos de un millar de personas) excede el que permite mantener una relación de vecindad entre sus habitantes, y que es ocupado por gentes de distintos niveles sociales, que desarrollan actividades especializadas de diferentes tipos (agrícola, artesanal, administrativa, religiosa, militar)". Los datos que se presentan en las páginas siguientes demuestran que Masies de Sant Miquel encaja dentro de esta definición, lo que a su vez permite verificar la complejidad de las formas de ocupación y control de los territorios costeros del nordeste peninsular durante el período ibérico.

\section{SITUACIÓN DEL YACIMIENTO E HISTORIA DE LA INVESTIGACIÓN}

El yacimiento conocido como "Les Masies de Sant Miquel" toma su nombre de un arrabal de Banyeres del Penedès, situado a unos $2 \mathrm{~km}$ al sudoeste de esta población de la comarca del Baix Penedès (Tarragona), a unos 5,5 km al noroeste de la capital comarcal, El Vendrell, y a unos $13 \mathrm{~km}$ en línea recta de la línea de costa (Figs. 1-2). Se encuentra cerca del extremo sudoriental de la depresión prelitoral catalana, la gran vía de circulación que discurre entre los Catalánides y conecta los llanos prepirenaicos con la ciudad de Tarragona, a través de las comarcas del Ampurdán, Gironès, la Selva, Vallès y Penedès. Asimismo, puede comunicar fácilmente con la costa por dos vías distintas: al norte, a través del torrente de Marmellar, que fluye a unos $3 \mathrm{~km}$ y desemboca en el río Foix, el cual, después de atravesar la sierra litoral, desagua en el Mediterráneo por Cubelles; al sur, el torrente de Sant Miquel, que, como se ha dicho, discurre junto al yacimiento y desemboca a la altura de El Vendrell en el torrente de la Bisbal, que a su vez alcanza el Mediterráneo en Sant Salvador. Además de su excelente situación en relación con las vías de comunicación, el yacimiento se encuentra en una posición central en la llanura del Penedès, en medio de una extensa zona agrícola, hoy en día ocupada mayormente por plantaciones de viña. A estas ventajas económicas de su ubicación se contrapone una evidente vulnerabilidad, al ocupar el asentamiento un terreno llano, tan solo protegido al sudeste por el curso encajado del torrente de Sant Miquel (Figs. 3-4) -que constituye un obstáculo importante-, y al oeste y sudoeste por una depresión que, como se verá, puede ser el resultado de la excavación de un foso defensivo en época protohistórica. Junto a esta última discurre una pequeña corriente producto de canalizaciones modernas en la zona.

Masies de Sant Miquel constituye un auténtico complejo arqueológico, compuesto por distintos yacimientos situados en una amplia zona que se extiende al oeste y sudoeste del núcleo actual de población, entre la autopista AP-7, al noroeste, y, al sudeste, la partida de la Garita Vella, al otro lado del torrente de Sant Miquel (Figs. 3-4). Es una zona básicamente llana, dominada por una pequeña elevación (El Pujol, de $143 \mathrm{~m}$ s. n. m.), de suaves pendientes y altitud relativa de unos $25 \mathrm{~m}$ en relación con las planas que se 


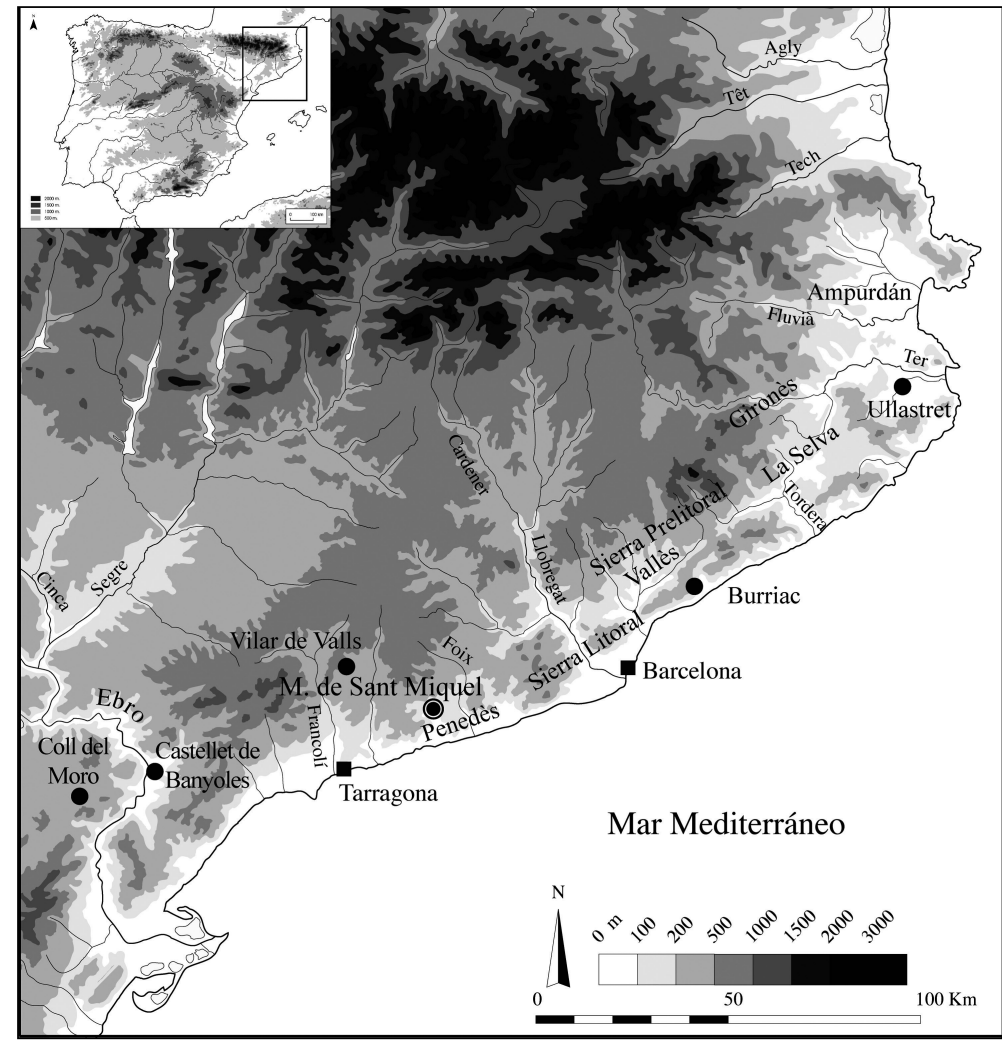

Figura 1. Situación de Masies de Sant Miquel (Banyeres del Penedès, Tarragona) en el contexto de la Iberia septentrional (elaboración propia).

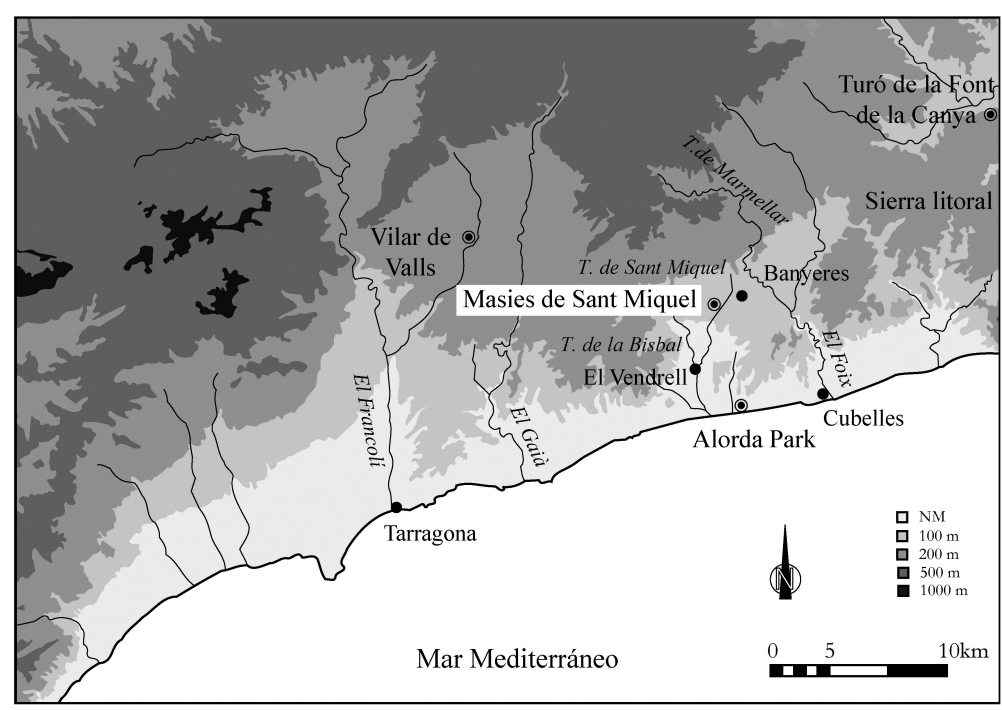

Figura 2. Mapa de la Cesetania con la situación del yacimiento de Masies de Sant Miquel (elaboración propia). extienden inmediatamente al sur y al sudeste.

En el flanco nordeste de El Pujol, y a unos $500 \mathrm{~m}$ de la finca rústica de Can Canyís, se encontraba, según el plano publicado por Vilaseca, Solé y Mañé (1963: 11, fig. 2), la necrópolis paleoibérica de incineración del mismo nombre, excavada en 1961 y 1962, cuando se hallaba ya en gran parte destruida por trabajos agrícolas. Tan solo fue posible documentar los restos de cuatro depósitos funerarios, uno de los cuales fue interpretado como una tumba de guerrero; se recogió también un importante conjunto de materiales dispersos, que han permitido evaluar hipotéticamente el total de tumbas entre quince y veinte (Bea et alii 1996: 51). Dichos materiales, publicados ya en parte por sus descubridores (Vilaseca et alii 1963), han sido objeto de diversos estudios por otros investigadores (Bea 1996; Bea et alii 1996; Munilla 1991; Padró 1971 y 1980).

Los excavadores de la necrópolis señalaron también la existencia de abundante cerámica ibérica y romana, e incluso de restos de construcciones, entre la finca de Can Canyís y el núcleo de Masies de Sant Miquel, al este de la necrópolis, y también en la zona de la Garita Vella, unos 400 $\mathrm{m}$ al sudeste. De esta última proceden, al menos en teoría ${ }^{11}$, dos fondos de vasos de barniz negro del taller de Rhode, decorados respectivamente con palmetas $\mathrm{y}$ con una roseta impresas, que se conservan en la sede barcelonesa del Museu d'Arqueologia de Catalunya y que fueron publicados por

\footnotetext{
11 Desconocemos el origen de este depósito en el MAC. En la zona conocida actualmente como la Garita Vella no se han recogido materiales anteriores al período imperial, por lo que cabe suponer una confusión de orden toponímico, y que en realidad estas piezas fueran halladas más al suroeste, donde se encuentra el yacimiento ibérico.
} 
E. Sanmartí Grego (1978a, vol. II, 682, lám. 98, 17 y $38 ; 1978$ b, 26, fig. $\left.4, n^{\circ} 5\right)$. Actualmente se puede confirmar la existencia de una amplia dispersión de material cerámico en las zonas mencionadas, pero no de restos de construcciones. Los autores del mencionado trabajo no consideraron, sin embargo, que se pudiera tratar de un asentamiento relacionado con la necrópolis, y tampoco hicieron referencia alguna a la zona de mayor dispersión de materiales arqueológicos, que se extiende sobre el margen derecho del torrente de Sant Miquel, en un amplio espacio (unas 3,5 ha), de perfil vagamente arriñonado, definido, al este y al sur, por los dos torrentes antes mencionados, mientras que por el costado noroeste este espacio se prolonga sin solución de continuidad en dirección al arrabal de Masies de Sant Miquel.

El espacio ocupado por el asentamiento se compone de dos partes separadas por un estrangulamiento en la parte oriental; la meridional, de unos $200 \mathrm{~m}$ de longitud por unos $100 \mathrm{~m}$ de anchura (unas 2 ha) está orientada casi exactamente en dirección norte-sur; la septentrional está orientada en dirección nordestesudoeste y mide unos 150 por $100 \mathrm{~m}$ (unas 1,5 ha) (Figs. 3-4). Los materiales esparcidos sobre este amplio espacio son principalmente cerámica ibérica y cerámica de importación del período ibérico, pero existe también en el extremo nororiental una zona más reducida ( 0,6 ha), en torno a la ermita de Sant Miquel, donde se documenta una importante presencia de cerámica de época romana imperial, ya reconocida en su día por Ferrer y Giró (1943) y por Solé Caralt (1948, no 63 y 104; 1952, 217, nº 299-300), además de algunos restos de muros y un potente pavimento de opus signinum reutilizados en la construcción de la ermita y de un edificio anejo a la misma (Carrasco et alii 1995

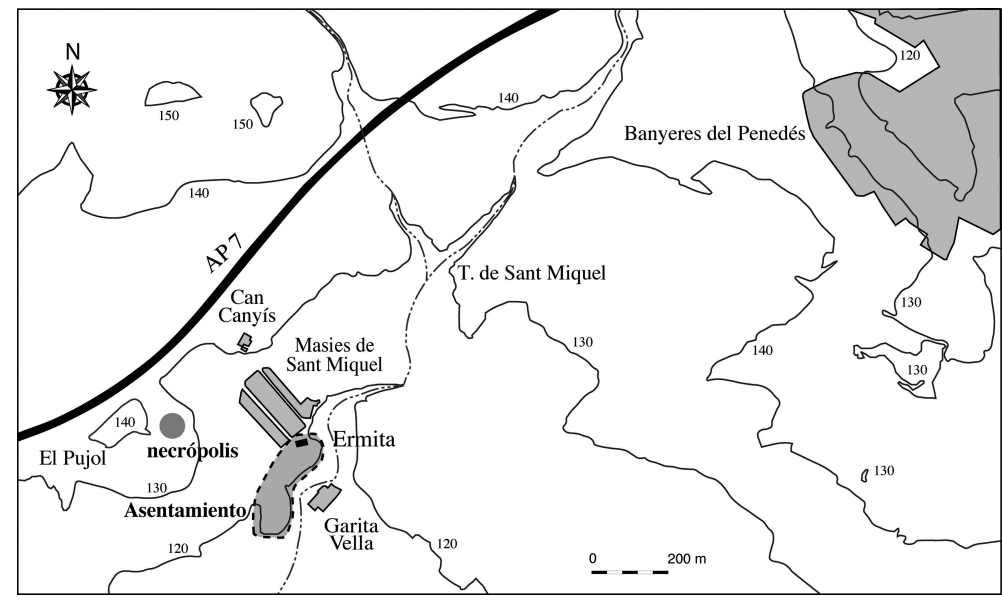

Figura 3. Situación de Masies de Sant Miquel en el contexto local (elaboración propia).
5-6). El notable volumen de material romano, que se extiende también a la ribera izquierda del torrente de Sant Miquel, en la zona conocida como la Garita Vella, ha llevado a pensar que se trataba de un asentamiento importante, probablemente una villa formada por edificaciones de carácter residencial y estructuras productivas (Carrasco et alii 1995: 5). Además de la ermita y construcciones anexas, existen al suroeste de las mismas dos casas edificadas en los años 80 (Fig. 4). El resto del yacimiento, sin embargo, se encuentra aparentemente libre de edificaciones posteriores a las etapas ibérica y romana.

En 1987, la excavación de una zanja a unos $25 \mathrm{~m}$ al suroeste de la ermita reveló la existencia de una compleja estratigrafía, de unos $2 \mathrm{~m}$ de potencia. Ello motivó una intervención de urgencia, bajo la dirección de P. Carrasco, L. Pallejà y V. Revilla, que se tradujo en un pequeño pero importante sondeo (Carrasco et alii 1995). Los resultados permitieron documentar cuatro fases distintas, pero sin solución de continuidad, escalonadas entre la Primera Edad del Hierro y un momento difícil de determinar, pero que probablemente se sitúe en torno a 200 a. C., o poco después. En el mismo aparecieron distintos muros, sobre todo de las fases más recientes, pertenecientes aparentemente a construcciones domésticas, pero la escasa extensión del sondeo impidió comprender claramente su estructura. Entre los materiales fechables dentro del siglo VI a. C. destacan dos fragmentos de copa pseudojonia (Alaminos et alii 1991: 293, figs. 9, 3 y 5; Sanmartí et alii 2002: 89, figs. 18,4 y 6) y un borde de ánfora púnico-ebusitana tipo PE 10/10.1.2.1 (Alaminos et alii 1991: 292, fig. 8, 3; Sanmartí et alii 2002: 76, fig. 5, 3); a ellos puede añadirse un fragmento de borde de copa tipo Loeschke C hallado en la misma zona, aunque en superficie (Alaminos et alii 1991: 293, fig. 9, 4; Sanmartí et alii 2002: 82, fig. 11, 6). La fase de siglo VI a. C. se relaciona sin duda con la anteriormente mencionada necrópolis de Can Canyís. Los niveles de esta cronología se superponen a un primer momento de ocupación, directamente sobre la roca natural, en el que se documenta exclusivamente cerámica a mano de la Primera Edad del Hierro y ánfora fenicia de la zona del estrecho de Gibraltar, lo que permite fecharlo entre el siglo VII y los primeros decenios del siglo VI a. C. Esta continuidad y la buena conservación aparente de los restos, junto con la presencia de la necrópolis, permiten suponer 


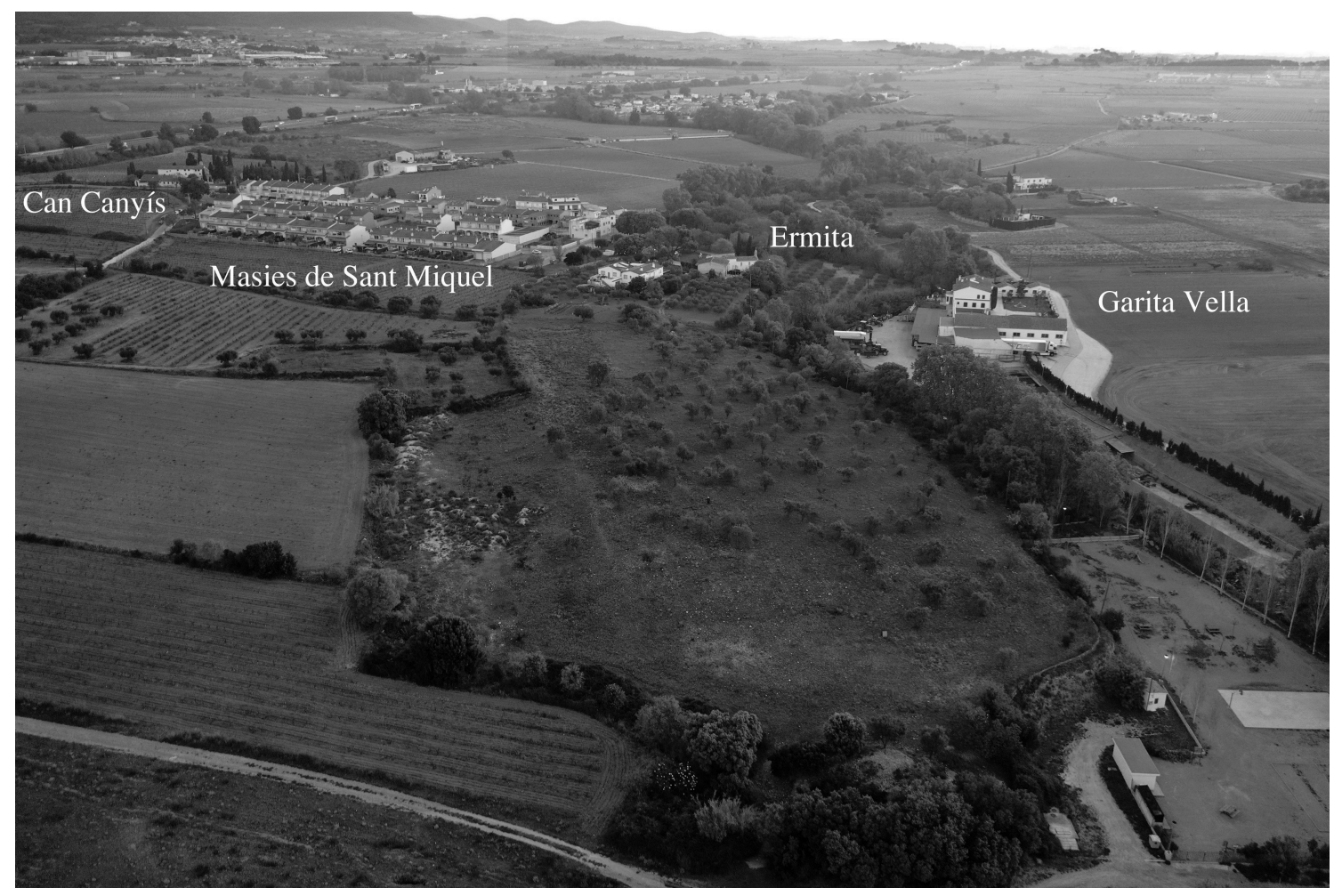

Figura 4. Vista aérea del yacimiento desde el suroeste (elaboración propia).

que se trata de un yacimiento fundamental para el estudio de las profundas transformaciones sociales experimentadas por las comunidades locales de esta zona a lo largo del siglo VI a. C.

En 1998, la excavación, sin autorización administrativa, de una balsa de regadío, a unos $35 \mathrm{~m}$ al oeste del sondeo de 1987, motivó una nueva intervención de urgencia en la misma finca. Esta excavación, realizada bajo la dirección de X. Cela, puso de manifiesto, en una superficie irregular de unos 19 por $9 \mathrm{~m}$, la existencia de diversos muros seccionados por la excavadora, así como una potente sedimentación antrópica de espesor comprendido entre 3,5 y 4,5 m (Adserias et alii 2000-2001: 257; Cela et alii 2001). La intervención se limitó a la limpieza de estructuras y perfiles estratigráficos, pero trajo a luz un muro de $1,90 \mathrm{~m}$ de anchura y otros de 0,80 a $1 \mathrm{~m}$, que parecen corresponder a una estructura defensiva, además de otras paredes de menor grosor (en torno a 0,40 m), atribuibles a construcciones domésticas. La destrucción provocada por las excavadoras y el hecho de que la intervención se centrara en el trabajo de limpieza y documentación impiden comprender claramente la estructura de estos restos. Los materiales recuperados corresponden en su gran mayoría al siglo III a. C., y el pequeño conjun- to que se pudo recuperar en el nivel de destrucción 1020 sugiere que el final del poblado se produjo en torno a 200 a. C.; sin embargo, el hallazgo en otros niveles de una copa Cástulo indica también una ocupación anterior, del siglo $\mathrm{V}$ a. $\mathrm{C}$.

Entre 1998 y 2005, el Servei d'Arqueologia de la Generalitat de Catalunya promovió la realización, bajo la dirección de M. Adserias e I. Teixell (CODEX-Arqueologia i Patrimoni), de una serie de trincheras de prospección, con objeto de determinar la extensión del yacimiento de cara a una declaración del mismo como Bien Cultural de Interés Nacional, que se produjo en el año 2011. El resultado fue la comprobación de que existían restos de construcciones en toda la zona de dispersión de material cerámico antes descrita (Adserias et alii 2000-2001: 257).

A ello se añade una prospección con georradar realizada por L. Marí (Arqueoradar SCP), que afectó una amplia zona entre la casa situada al oeste de la ermita, el núcleo de Masies de Sant Miquel y la autopista AP7, incluyendo pues la pequeña elevación de El Pujol. Se detectó la existencia de anomalías atribuibles a restos arqueológicos en una amplia extensión de terreno, situada en la parte oriental de la zona mencionada; otras, tal vez relacionadas, a tenor de su discon- 
tinuidad espacial, con la necrópolis, se documentaron en la zona de El Pujol; finalmente, en un espacio más reducido situado entre El Pujol, Can Canyís y Masies de Sant Miquel, se detectó la existencia de una serie de estructuras excavadas que pueden corresponder a un campo de silos (Adserias et alii 2000-2001: 271), o bien a actividades agrícolas modernas.

En resumen, con los datos disponibles antes de los trabajos que se presentan en este artículo había elementos suficientes para suponer la existencia en Masies de Sant Miquel de un asentamiento ibérico en buen estado de conservación y de entidad considerable (unas 3,5 ha), tan solo por detrás de Tarragona y el Vilar de Valls ${ }^{12}$ en la escala de tamaños de la antigua Cessetania (Sanmartí 2014; Sanmartí et alii 2015). Esta última era una de las tres entidades político-territoriales de carácter centralizado que ocupaban la zona costera de la actual Cataluña y que creemos pueden entenderse como ciudades-estado (Sanmartí 2014; Sanmartí et alii 2019).

El poblamiento de su entorno estaba constituido en gran parte por granjas y otros asentamientos rurales cuya naturaleza y funciones se han ido documentando paulatinamente en los últimos decenios (Ferrer et alii 2003; Asensio et alii 2005b), pero que incluye también algún núcleo de control político-militar de escala micro-regional, como Alorda Park (Sanmartí y Santacana 1992; Asensio et alii 2005c), además de centros de acumulación de excedentes agrícolas (Asensio et alii 2005a). Todas estas razones -lo conocido del propio asentamiento y su posición en el sistema de poblamiento-justificaron su inclusión entre los yacimientos a analizar en nuestro proyecto sobre la formación y evolución de las ciudades ibéricas en el nordeste peninsular.

\section{LOS TRABAJOS DE PROSPECCIÓN}

Los diferentes trabajos de prospección, ejecutados entre marzo y mayo de 2018, se han centrado en la zona meridional del asentamiento, al sur del estrangulamiento mencionado anteriormente en la descripción del mismo. En total, han afectado unas 2 ha, totalmente libres de edificaciones, pero en gran parte ocupadas por una plantación de almendros (Fig. 5). En primer lugar, se realizó una prospección con aparatos detectores de metales y ubicación de los objetos localizados mediante instrumentos GPS portátiles de precisión métrica, suficiente para determinar de manera signi-

12 Trabajos recientes de prospección geofísica, aún inéditos, realizados en el marco del ya mencionado proyecto CAUCIS, confirman una extensión cercana a las 6 ha. ficativa la ubicación del material en superficie. A continuación, se desarrollaron los trabajos de prospección pedestre intensiva, y finalmente se ejecutó la prospección geofísica.

La prospección electromagnética se realizó por un equipo de seis personas, equipadas con cinco detectores de metales Teknetics T2, cinco pinpointers Deteknix XPointer, y cinco GPS Garmin Etrex 30x, con el objetivo de recuperar únicamente los objetos metálicos procedentes de los niveles superficiales. Después de un día de trabajo resultó evidente que el yacimiento había sido sistemáticamente expoliado por furtivos provistos de detectores de metales (conclusión posteriormente confirmada por los vecinos de Masies de Sant Miquel), ya que no se recuperó ni un solo objeto metálico relacionado con la ocupación ibérica. Por ello, se reformuló el plan de trabajo y se pasó a prospectar la zona alrededor de la ermita, con el objetivo de recuperar y situar materiales cerámicos relacionados con la villa imperial, y la zona elevada del Pujol, para intentar localizar posibles restos de la necrópolis de Can Canyís.

En cuanto a la necrópolis, es sabido que los enterramientos fueron destruidos por una transformación agrícola realizada con tractores en los años 60, con el propósito de sustituir árboles de secano por vides. La comparación de las fotografías aéreas de 1956 con las tomadas en 1983 permitió comprobar que el cambio de cultivos solo se dio en una parcela de 1 ha, situada a $225 \mathrm{~m}$ al sudeste del manso de Can Canyís, y a $250 \mathrm{~m}$ al nordeste del asentamiento ibérico. La prospección de esta zona proporcionó un pequeño conjunto de cerámica ibérica (33 fragmentos a torno y 7 a mano), junto con dos pequeños eslabones de bronce, uno de ellos con apéndice esferoidal, en un área reducida, de $700 \mathrm{~m}^{2}$, sin duda correspondiente a la necrópolis paleoibérica. Dado que en este sector la roca natural aflora por todas partes, hay que concluir que la zona de enterramientos se encuentra completamente arrasada.

La siguiente fase consistió en la prospección pedestre. En primer lugar, se instaló una retícula constituida por cuadros de $10 \times 10 \mathrm{~m}$, materializada con estacas situadas mediante un dispositivo GPS Leica Zeno 5 de precisión centimétrica. Su adaptación al terreno provocó que algunos cuadros fueran de tamaño inferior, de modo que en total se cubrió una superficie real de 1,75 ha (Fig. 6). Las unidades de prospección se designaron a partir de la intersección de ejes perpendiculares, identificados respectivamente mediante letras (norte-sur), y números arábigos (esteoeste). Las condiciones de visibilidad eran excelentes, ya que un mes antes de la prospección se labró superficialmente el terreno, coincidiendo además con una temporada de lluvias. 


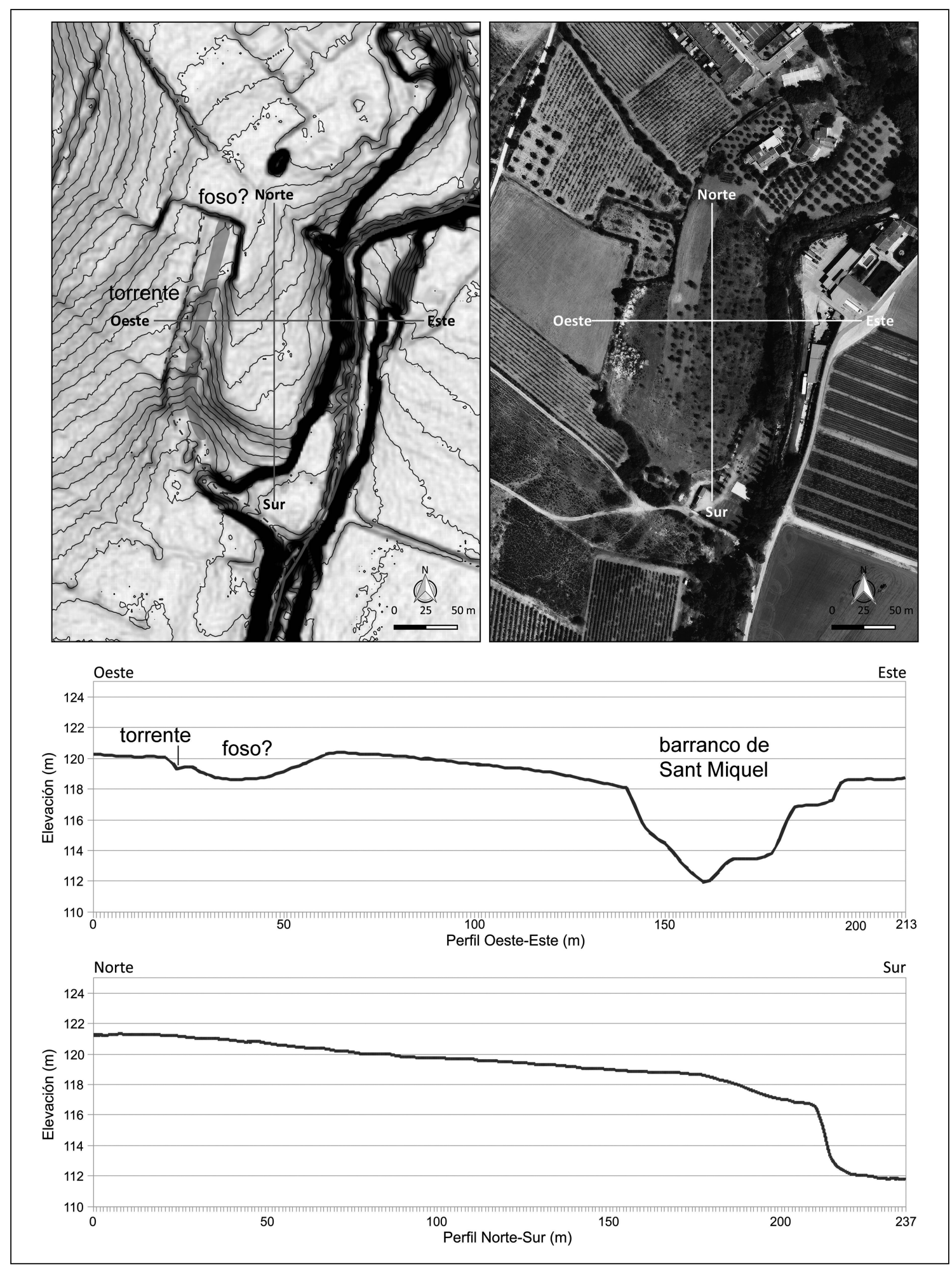

Figura 5. Modelo digital del terreno, ortofotografía y perfiles topográficos del yacimiento (base: Institut Cartogràfic i Geogràfic de Catalunya) (elaboración propia). 


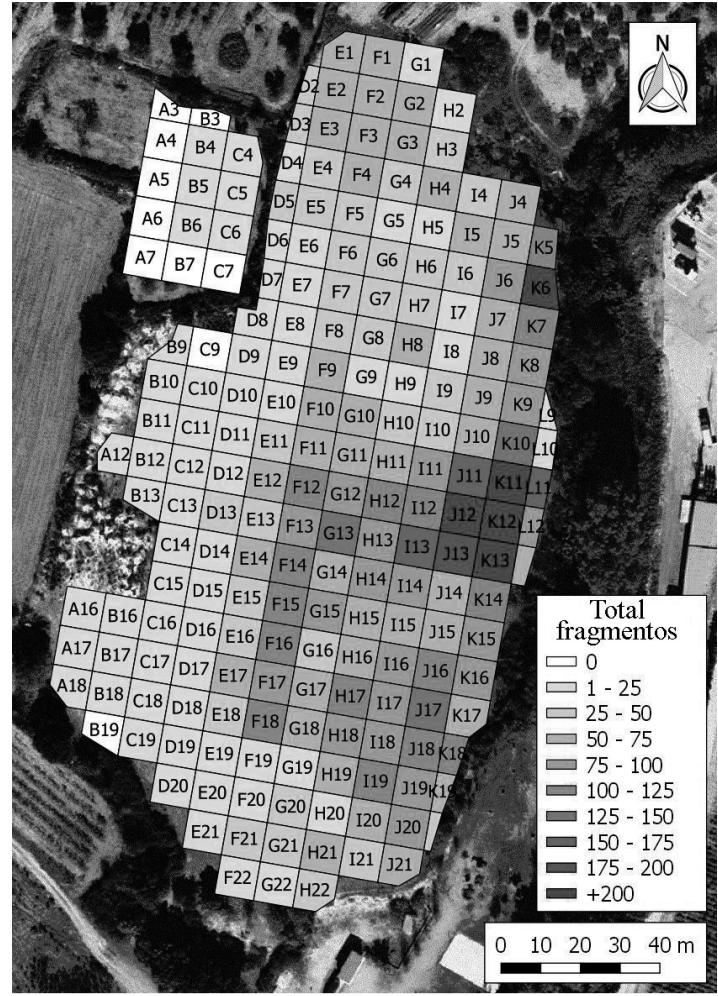

Figura 6. Cuadrícula de prospección pedestre, con indicación del número de hallazgos (elaboración propia).

Se realizó en esta zona una cobertura total, con separación entre prospectores muy reducida, de apenas $2 \mathrm{~m}$, y por lo tanto con una intensidad muy elevada. El equipo estaba formado por dos grupos de cinco personas, y se recogieron absolutamente todos los objetos arqueológicos, sin ningún tipo de sesgo. Se recuperó un total de 10.824 fragmentos cerámicos, con una densidad media muy elevada, próxima a 0,62 fragmentos por metro cuadrado. A título comparativo, la prospección realizada, en el marco del mismo proyecto, sobre el núcleo urbano del Coll del Moro (Gandesa, Tarragona) ofrece una densidad de casi 0,5 fragmentos por metro cuadrado. Sin embargo, la concentración de material cerámico varía en gran medida según las zonas (Fig. 6). Así, en el sector oriental, junto al barranco de Sant Miquel, alcanza los 5 fragmentos por metro cuadrado. En cambio, la cifra se reduce drásticamente en el sector occidental, en concreto en el paso de la columna E a la columna $\mathrm{D}$, sin que exista una razón evidente para esta variabilidad. A partir de la columna D los valores decrecen paulatinamente, por debajo de 0,3 en la columna D, inferiores a 0,1 en las columnas $\mathrm{C}$ y B, y cercanos a cero en la columna $\mathrm{A}$, que constituye el límite occidental del yacimiento. Por otra parte, también reconocemos el posible límite meridional a tenor de la reducción progresiva de material a partir de las filas 19 a 22.

Durante la prospección pedestre también se identificaron tres silos en el cuadrante noreste, uno de ellos sin duda vacío. Por último, el terreno situado entre B9 y B19 está claramente deprimido respecto a su entorno inmediato, ya que en este punto presenta una cota entre 2 y 3 m inferior, en una longitud cercana a los $100 \mathrm{~m}$. Como se ha dicho, tal vez ello indique la presencia de un foso.

\section{ESTUDIO DEL MATERIAL}

Del total de 10.824 fragmentos cerámicos recuperados, $10.349(95,6 \%)$ corresponden a las distintas producciones ibéricas (oxidada y reducida a torno, cerámica de cocina a torno, cerámica a mano) y 432 (4,4 \%), a vasos de importación (vajilla, ánforas y cerámica común). En un recuento por individuos (no ponderado), el porcentaje de importaciones aumenta significativamente, hasta el $14 \%$ (57 individuos, por 356 de producción local); ello se debe probablemente al hecho de que, como se verá más adelante, una parte muy importante de los vasos de producción ibérica corresponde a recipientes de tamaño grande y mediano (ánforas sobre todo), con un elevado índice de fragmentación, mientras que entre las importaciones predomina la vajilla (35 individuos $=61 \%$, por un $32 \%$ de las ánforas -18 individuos- y un $7 \%$ de la cerámica "común" -12 individuos-).

\section{I. LA CERÁMICA DE IMPORTACIÓN}

En lo que a la vajilla se refiere, las producciones representadas son la cerámica ática, siempre de barniz negro (10 fragmentos $=10 \%$ de la vajilla importada; 7 individuos $=20 \%$ de la vajilla importada), la cerámica de barniz negro del taller de Rhode (37 fragmentos $=35 \% ; 10$ individuos $=28 \%$ ), la cerámica de barniz negro de producción púnica ( 2 fragmentos $=2$ $\% ; 2$ individuos $=6 \%) \mathrm{y}$, sobre todo, la campaniense A $(55$ fragmentos $=53 \% ; 15$ individuos $=43 \%)($ Fig. 7). Las formas representadas de campaniense A (23, 27B, 27ab, 28, 36, 68 i 12823) son características de la fase antigua de esta producción (220-180 a. C.) y, aunque todas ellas (salvo el plato de pescado y la pátera 12823) perduran en la subsiguiente fase media (180-100 a. C.), es preciso observar que ninguna de las nuevas formas surgidas durante esta última está representada en el yacimiento. 


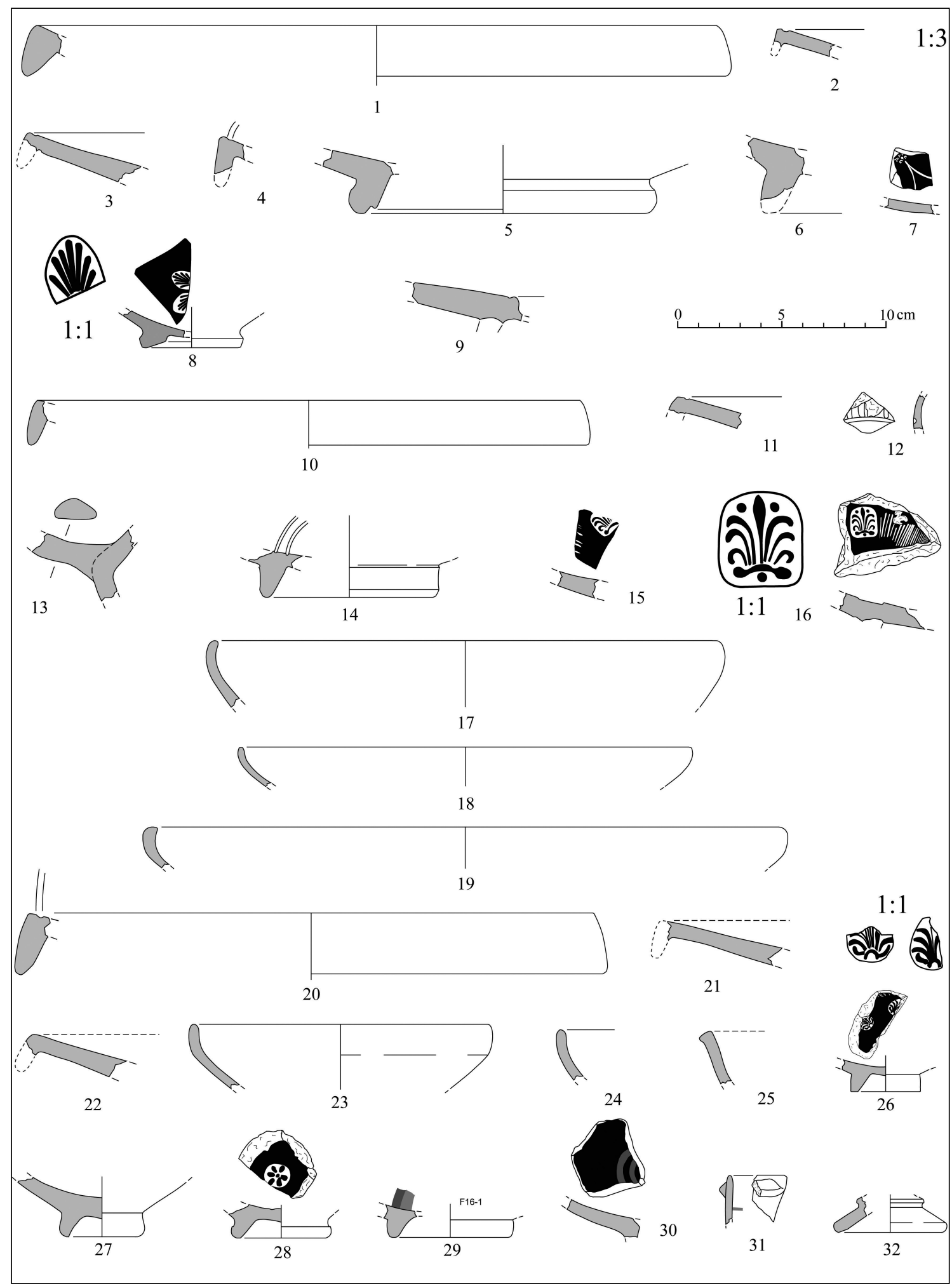

Figura 7. Cerámica de barniz negro: ática (1-7); púnica (8-9); Taller de Rhode (10-19); campaniense A (20-32) (elaboración propia). 


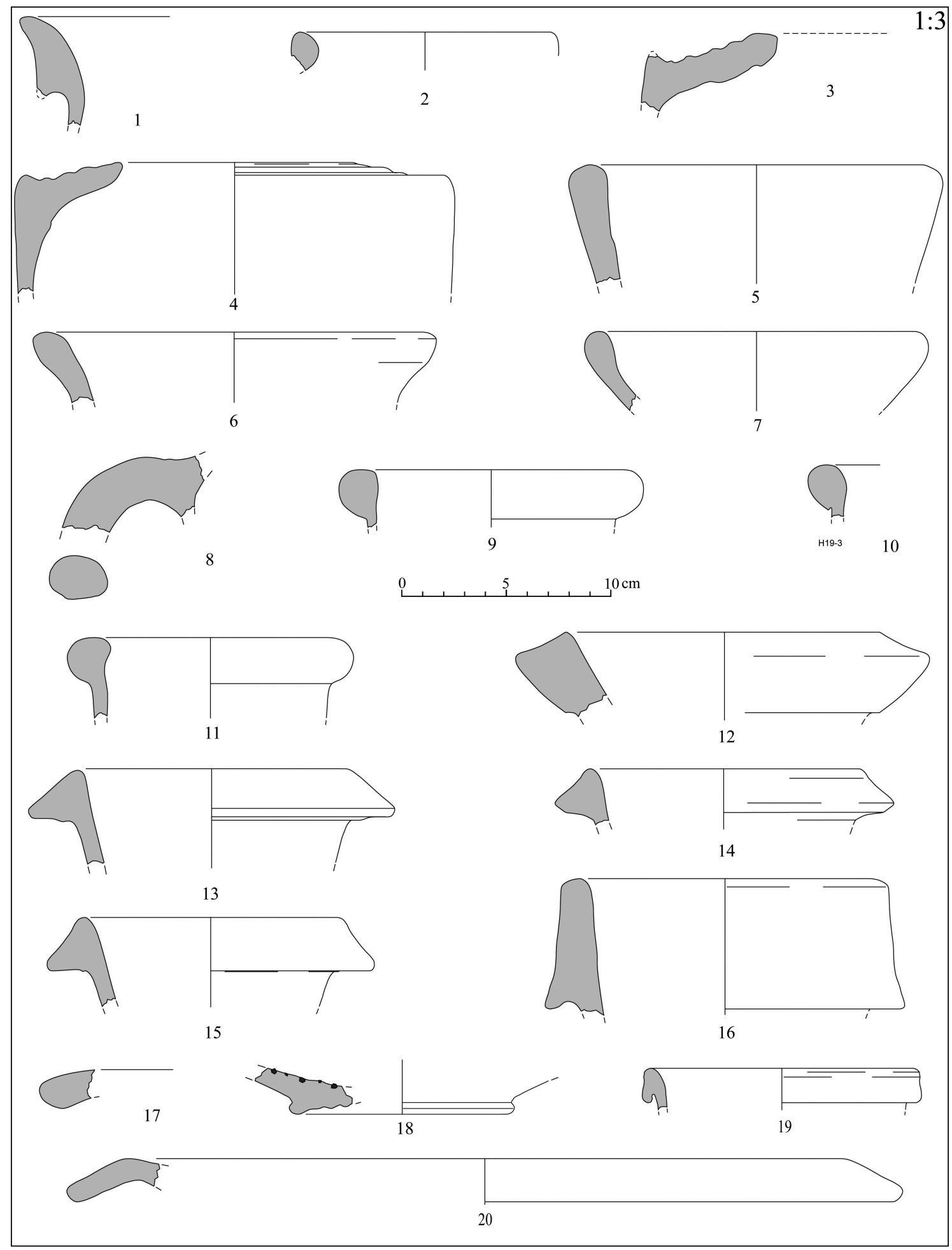

Figura 8. Ánfora púnica del Mediterráneo central (1-4); Ánfora púnica del Círculo del Estrecho (5-8); Ánfora púnica ebusitana (9-11); Ánfora masaliota (12); Ánfora greco-itálica e itálica (13-16); cerámica común: púnica del Círculo del Estrecho (17); púnica ebusitana (18); púnica del Mediterráneo central (19-20) (elaboración propia). 
Las ánforas de importación (Fig. 8) están representadas por un total de 306 fragmentos, en su gran mayoría atribuibles a producciones púnicas: centromediterránea ( 75 fragmentos $=24 \%)$, ebusitana $(118$ fragmentos $=38 \%$ ) y del Círculo del estrecho de Gibraltar $(18$ fragmentos $=6 \%)$. La producción masaliota está representada por tan solo dos fragmentos (1 $\%)$, mientras que el ánfora itálica constituye otro grupo importante, con 91 (= $30 \%)$. Tres de los cuatro bordes atribuibles a esta última producción corresponden a ánforas grecoitálicas de tipo antiguo (Fig. 8: 13-15), y el otro a una pieza de forma Dr. 1B (Fig. 8: 16), de cronología evidentemente más avanzada. Representan en conjunto el $28 \%$ de los individuos anfóricos, cifra próxima a la obtenida a través del recuento de fragmentos $(30 \%)$. A ello debe añadirse dos fragmentos de producción indeterminada $(1 \%)$.

La cerámica común de importación (Fig. 8) está representada por un borde de mortero, con pasta idéntica a la de las ánforas púnicas del Círculo del estrecho, una base de mortero ebusitano, un borde de jarro de cerámica púnica, probablemente de la zona de Túnez, un borde de mortero de la misma procedencia (Fig. 8: 17-20), y un pequeño fragmento de fondo de una patina itálica. Aunque minoritarios, estos vasos representan un $9 \%$ de las formas de cerámica importada. Cabe destacar la ausencia de cerámica de cocina cartaginesa, relativamente frecuente en los niveles del siglo III a. C., en ciertos yacimientos (Sanmartí y Asensio 2005; Asensio 2004).

\subsection{LA CERÁMICA DE PRODUCCIÓN LOCAL Y/O REGIONAL}

Dentro de este conjunto, la cerámica a torno oxidada representa una abrumadora mayoría (10.307 fragmentos $=99 \% ; 340$ individuos $=96 \%$ ), seguida por la cerámica de cocina a torno (16 fragmentos $=0,15 \% ; 7$ individuos $=2 \%)$, la cerámica a mano (66 fragmentos $=$ $0,66 \% ; 5$ individuos $=1 \%$ ), y la cerámica a torno reducida (9 fragmentos $=0,19 \% ; 4$ individuos $=1 \%$ ). Debe reseñarse también que la cerámica con decoración pintada supone un pequeño porcentaje de los vasos oxidados (17 individuos $=5 \%$ ).

El repertorio documentado dentro de la cerámica a torno (que puede considerarse como un conjunto, incluyendo las piezas de cocción reductora) presenta peculiaridades importantes desde el punto de vista cuantitativo. En efecto, las ánforas ibéricas, con 176 individuos (Fig. 9: 1-8), representan el $52 \%$ de estos vasos, seguidas a gran distancia por vasos grandes o medianos dotados de los característicos bordes con sección de "cuello de cisne" (42 individuos = $12 \%)$
(Fig. 9: 9, 11 y 13) y de otros recipientes de boca ancha y borde acanalado, también de dimensiones grandes o medianas (25 individuos $=7 \%$ ) (Fig. 9: 16, 18). Los kalathoi (Fig. 8: 17, 19), así como las sítulas (Fig. 9: $10,12)$, están relativamente bien representados $(19$ y 21 individuos respectivamente $=5 \%$ y $6 \%$ ). Los elementos de vajilla representan, en cambio, un volumen reducido del total: tan solo 21 jarras $(6 \%), 17$ cuencos/ páteras (5 \%) (Fig. 10: 11-15), dos jarritas bitroncocónicas (1\%) (Fig. 10: 2, 4, 6, 9-10), 3 vasitos de forma imprecisa $(1 \%)$ y, por último, cuatro piezas cuyo perfil puede inspirarse en los platos de pescado (hipótesis abonada también por la frecuencia de esta forma entre los vasos de barniz negro hallados en el yacimiento) (4 individuos $=1 \%$ ) (Fig. 10: 1, 3, 5). En conjunto, pues, los elementos de vajilla representan solo el $14 \%$ de los individuos de cerámica a torno, lo que tal vez pueda deberse al uso importante de vasos de importación. A todo ello debe añadirse la presencia de dos morteros.

En relación con la cerámica de cocina a torno, tan solo cabe señalar que la única forma documentada es la olla con borde vuelto (Fig. 10: 16-18). La cerámica a mano presenta una diversidad algo mayor, en la morfología y en el tamaño de las piezas (Fig. 10: 19-23), pero la gran fragmentación del material impide otros comentarios.

\subsection{Algunas consideraciones Sobre los MATERIALES CERÁMICOS}

A pesar de tratarse de un conjunto procedente de recogida superficial, el material recuperado permite algunos comentarios relevantes sobre el yacimiento. En primer lugar, sobre la cronología del mismo, ya que, aparte de algún fragmento informe de ánfora del Círculo del estrecho con pasta de aspecto más bien arcaico -y que podría remontar al siglo VII a. C. o los primeros decenios de la centuria siguiente-, casi todo el material datable se sitúa entre los siglos IV y III a. C., y en particular dentro de esta última centuria. Esta es la cronología de las distintas producciones de barniz negro, incluyendo, como se ha visto, la campaniense A. Lo mismo se deduce de las importaciones anfóricas, donde predominan las piezas del siglo III a. C. avanzado, como las ánforas púnicas Ramon T-6121 (Fig. 8: 1), T-5231 (Fig. 8: 3-4) y T-8131 (Fig. 8: 9-11), y las ánforas grecoitálicas de aspecto antiguo (Fig. 8: 13-15). Las piezas de menor precisión cronológica, como las ánforas púnicas del Círculo del estrecho (Fig. 8: 5-8) y el ánfora masaliota de tipo 5 (Fig. 8: 12), son también compatibles con esta datación dentro del siglo III a. C. avanzado, aunque podrían remontar al siglo 


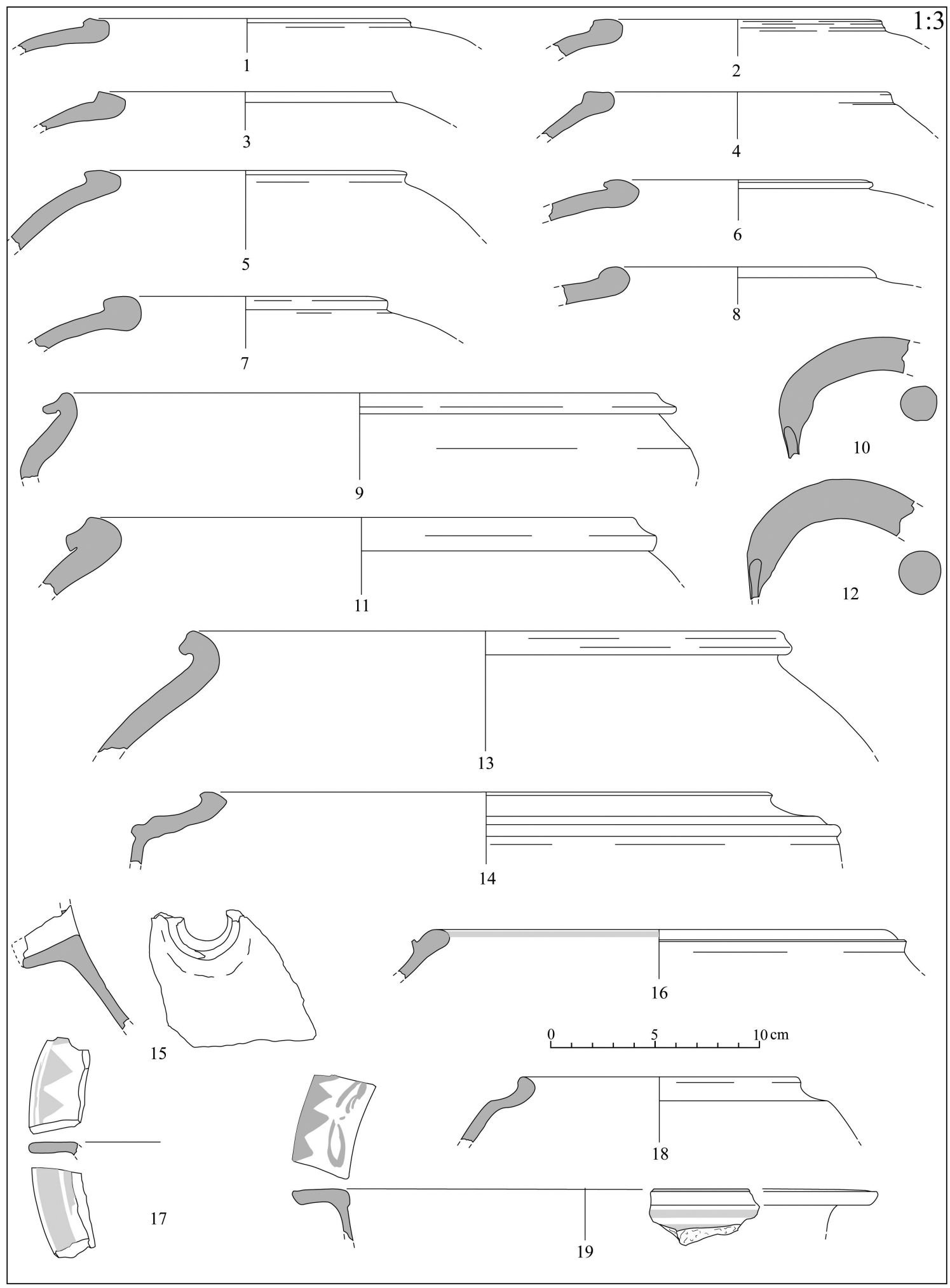

Figura 9. Cerámica ibérica oxidada (elaboración propia). 
LA CIUDAD IBÉRICA DE MASIES DE SANT MIQUEL (BANYERES DEL PENEDÈS, TARRAGONA)...

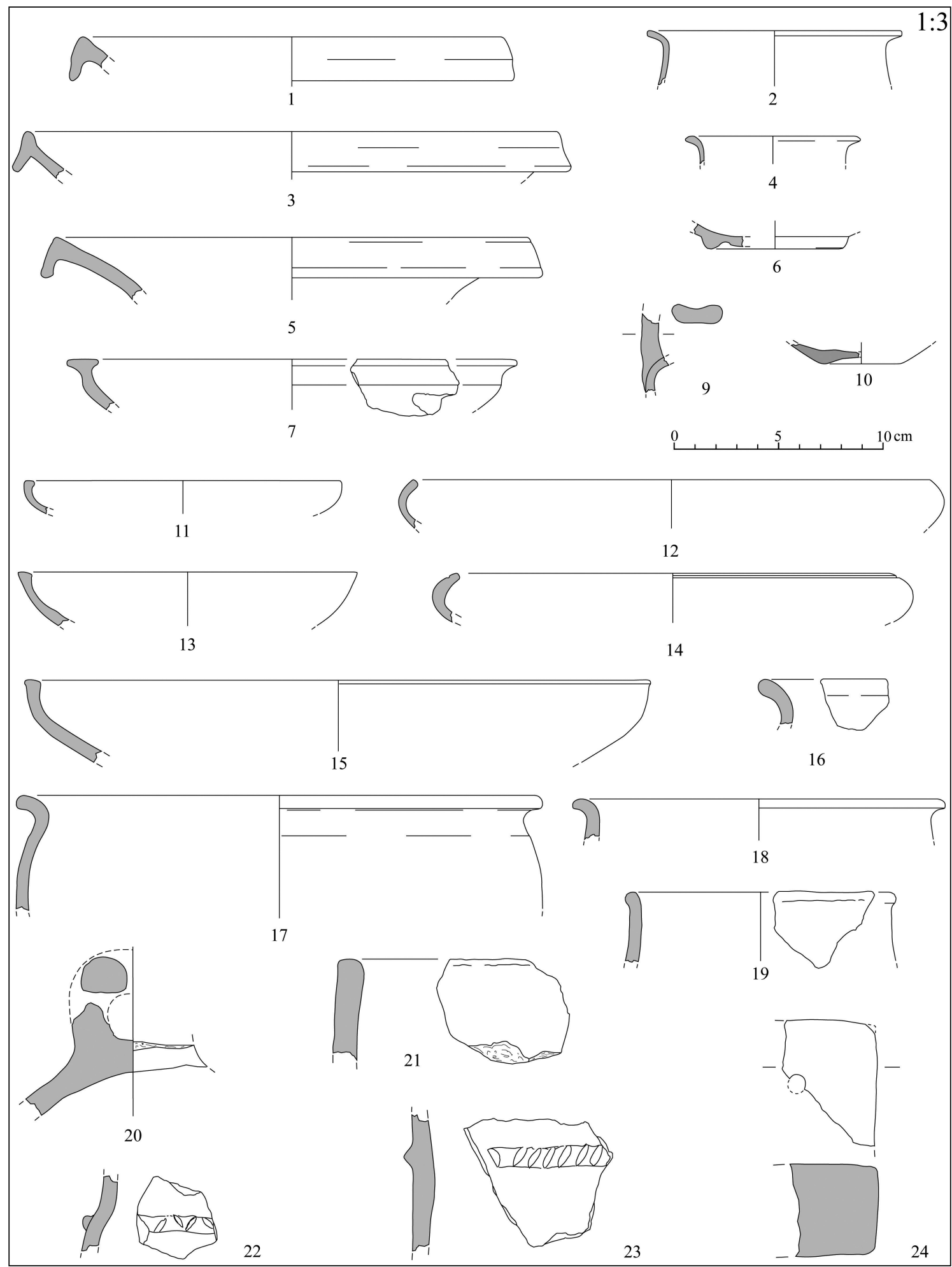

Figura 10. Cerámica ibérica oxidada $(1,3,5,7,11,13-15)$; cerámica ibérica reducida $(2,4,6,9,10,12)$; cerámica de cocina a torno (16-18); cerámica a mano (19-23); pondera (24) (elaboración propia). 
IV a. C. Lo mismo puede tal vez deducirse del reducido volumen de la cerámica a mano, de la presencia de vasos bitroncocónicos de cerámica gris de la costa catalana y de kalathoi, así como del aspecto de los bordes de un gran número de ánforas ibéricas, que por sus dimensiones reducidas y su sección de tendencia rectangular parecen corresponder a los tipos más tardíos de la zona, de siglo III a. C. (aunque perduran en la centuria siguiente) (Sanmartí et alii 1998). Todo ello confirma que, como ya se había propuesto con fundadas razones (Adserias et alii 2000-2001: 260-264; Cela et alii 2001: 258), el yacimiento fue abandonado (y tal vez destruido) en torno a 200 a. C., en conexión con los acontecimientos relacionados con la Segunda Guerra Púnica y las sublevaciones ibéricas, lo que confirma la naturaleza particularmente violenta de la ocupación por Roma de este territorio, y el profundo impacto que tuvo en los patrones de poblamiento (Sanmartí et alii 2012: 49-51). La presencia de algunas piezas aisladas de cronología más tardía, como el borde de ánfora de tipo Dr. 1B (Fig. 8: 16), puede tal vez explicarse por reocupaciones puntuales como las documentadas, por ejemplo, en Alorda Park (Sanmartí y Santacana 1992: 33-35), o incluso de menor entidad que estas. También es razonable suponer que una parte importante, incluso muy importante, de los materiales recogidos procede de niveles de la última fase del yacimiento, cuya superficie habría sido erosionada por la actividad agrícola. La presencia en el mismo de un número considerable de piezas áticas no obsta para ello, ya que estas aparecen a menudo en niveles del siglo III a. C. por su uso prolongado durante largos decenios. Por el contrario, tal vez sea significativa la ausencia de ánfora ebusitana del tipo PE 14 - Ramon T8111, siempre tan frecuente en los niveles del siglo IV a. C. de los yacimientos ibéricos del nordeste de la península ibérica.

Un segundo aspecto a destacar es el importante volumen de importaciones (14\% si cuenta por NMI), comparable al de otros yacimientos, como Ullastret o Alorda Park (Asensio 2015) donde diversos argumentos independientes permiten suponer una presencia importante de la elite social del período ibérico pleno. En el mismo sentido, es interesante observar que el número de piezas de vajilla ibérica (47) no es mucho mayor que el de la cerámica de barniz negro, e incluso netamente inferior si se detraen los 21 bordes de jarro, una forma inexistente entre la vajilla importada. Ello parecería confirmar un uso importante, desde el punto de vista cuantitativo, de la vajilla importada, lo que también sugiere un estatus social elevado de por lo menos una parte de la población de nuestro asentamiento. Todavía en relación con la cerámica de barniz negro, merece la pena observar el número considera- ble de platos de pescado (forma Lamb. 23) presentes en el conjunto estudiado (Fig. 7: 1-4, 10-11, 20-22). En efecto, cuatro de las siete piezas de cerámica ática corresponden a esta forma, que es muy rara en los yacimientos contemporáneos del nordeste peninsular (Sanmartí 2000). Estos platos siguieron siendo populares en Masies de Sant Miquel durante el siglo III a. C., con dos ejemplares del taller de Rhode $(17 \%$ de los vasos de esta producción) y otros cinco de campaniense A (un tercio de las piezas de esta producción); en ambos casos, la presencia de esta forma en los yacimientos de Cataluña es inferior (en el caso de la campaniense A, muy inferior) al documentado en nuestro yacimiento (Principal 1998: 95 y 142). Ello permite sospechar unas formas de consumo peculiares por parte de la elite que habitaba este gran asentamiento, que tal vez se puedan relacionar con las del mundo púnico, puesto que los platos de pescado son frecuentes en Cartago, por lo menos durante el siglo IV a. C. (Morel 1994: 330-331). Ello se compadece mal con la ya mencionada ausencia de vasos de cocina cartagineses - presentes en general en yacimientos donde se puede afirmar o sospechar la presencia de la elite social ibérica (Sanmartí y Asensio 2005; Asensio 2004; Sanmartí 2015)-, pero esta discrepancia puede deberse al azar de los hallazgos en recogida superficial.

La distribución de los restos cerámicos susceptibles de datación intrínseca es básicamente uniforme, de modo que no se puede reconocer claramente la existencia de áreas diferenciadas desde el punto de vista cronológico; de todas formas, cabe señalar que los elementos fechables inequívocamente con anterioridad al siglo III a. C. están prácticamente ausentes al sur de la fila 13 (tan solo algunos fragmentos de cerámica ática de barniz negro hallados en el cuadro G22, en el extremo meridional de la zona prospectada). Esto podría sugerir un crecimiento hacia el sur del yacimiento en el siglo III a. C., y dar sentido a la existencia -como se verá más adelante- de un buen número de construcciones extramuros. Con todo, pensamos que esta distribución particular de las cerámicas de importación debe de explicarse fundamentalmente por el azar de los hallazgos, ya que la misma ausencia de material anterior al siglo III a. C. se observa en las filas 14 a 17 , situadas total o parcialmente dentro del espacio amurallado.

Otro aspecto a comentar es el elevado número de ánforas ibéricas, que, como se ha dicho, constituyen más del $50 \%$ de los individuos de cerámica a torno de producción local o regional. Sin ser excepcional, este número proporcionalmente tan elevado de ánforas es muy superior al documentado en la mayoría de yacimientos con cuantificaciones fiables, y probablemente rebasa con mucho las necesidades de consumo local 
de la población de este asentamiento; ello sugiere la existencia en el mismo de actividades económicas especializadas y a una escala considerable; aunque no es posible precisarlas, puede suponerse que tuvieron relación, en parte al menos, con la transformación de productos agropecuarios en bebidas fermentadas.

En lo que se refiere a los materiales de época romana recuperados alrededor de la ermita de Sant Miquel, se trata en su inmensa mayoría de fragmentos con forma o decorados, producto, como se ha dicho, de una recogida selectiva, y georreferenciados mediante GPS. Casi todos los fragmentos pueden atribuirse, ya sea por su decoración (Fig. 11: 1-4) o por su forma, a producciones hispánicas. Son especialmente numerosos los bordes y bases de copas Hispánica 37 (Fig. 11: 5-6, 12 y 14-15), pero también de copas Hispánica 27 (Fig. 11: 8) y 29 (Fig. 11: 7). El tipo cerámico más antiguo de este periodo está representado por un fragmento de carena de una copa aretina indeterminada (Fig. 11: 9), seguido por otra carena de Drag. 15-17 de TS sudgálica (Fig. 11: 16). Finalmente, la vajilla más tardía está representada por la cerámica Africana Clara A, con dos bordes Lamb. 2a = Hayes 9A (Fig. 11: 13 y 17) y por la cerámica de cocina africana, en concreto un borde Lamb. 10A = Hayes 23B (Fig. 11: 18). Las distintas producciones de vajilla de mesa y los repertorios mencionados aparecen regularmente en contextos (bien datados) de finales de siglo I - primer tercio del siglo II d. C. en las villas del territorio y en Tarraco (Revilla 2014).

En definitiva, parece que los inicios de este asentamiento rural romano remontan a época augustea, más concretamente a principio del siglo I d. C., a partir de las sigillatas itálicas y sudgálicas. Ahora bien, la presencia mayoritaria de sigillatas hispánicas indica que el periodo de mayor auge corresponde a las postrimerías del siglo I d. C. y gran parte de la siguiente centuria, como también muestra la presencia de vajilla y cerámica de cocina africana.

\section{LA PROSPECCIÓN GEOFÍSICA}

La prospección geofísica se ha desarrollado exclusivamente sobre la parte meridional del espacio ocupado por el asentamiento ibérico, en concreto sobre 1,5 ha, prácticamente en la misma zona previamente prospectada a pie.

Los trabajos se iniciaron con una exploración encaminada a obtener información que orientara respecto a la metodología a aplicar, ya que era preciso tener en cuenta una serie de condicionantes específicos, como la vegetación, la topografía, o la base geológica. Efectivamente, los suelos arcillosos, la superficie irre- gular del terreno y la presencia de arbolado podían representar un problema en la resolución y en el alcance vertical del georradar; por tanto, la efectividad de la prospección se podía ver comprometida si los restos se encontraban a mucha profundidad o en mal estado de conservación. Por otro lado, la prospección magnética podía ser de utilidad en estas circunstancias, pero no se contaba con mediciones previas que permitieran inferir un buen contraste magnético de los materiales constructivos.

Para obtener esta primera muestra de datos se exploraron mediante prospección magnética dos zonas (un total de $4035 \mathrm{~m}^{2}$ ), ubicadas en las áreas central (grid B) y oeste (grid A) de la plataforma. La primera correspondía a la supuesta zona de hábitat, y la segunda al trazado de un posible sistema defensivo. La prospección se realizó mediante el sistema de gradiómetro tipo fluxgate Bartington G-601, con una resolución espacial de 0,25 x 0,5 m, es decir, 8 lecturas por metro cuadrado (Sala et alii 2012; 2013). Por otra parte, en la zona norte del área de estudio se cubrió una superficie de unos $3000 \mathrm{~m}^{2}$ con georradar equipado con 5 antenas de $600 \mathrm{MHz}$ en lectura simultánea, siguiendo el sistema IDS RIS -MOD. Los datos se han recuperado con una resolución de $0,02 \times 0,20 \mathrm{~m}$, es decir, obteniendo perfiles separados $20 \mathrm{~cm}$ entre sí, con una lectura cada $2 \mathrm{~cm}$ sobre toda la extensión a explorar (Sala et alii 2016).

Los datos obtenidos mediante prospección magnética permitieron la detección de numerosas anomalías de todo tipo, sobre todo correspondientes a fenómenos de alto contraste (restos de combustión u objetos férricos), pero con escasa definición para los restos constructivos. En general, los datos relativos a posibles estructuras en la zona central (grid B) son poco explícitos, pero los obtenidos del grid A muestran una anomalía de valores positivos en sentido norte-sur de manera discontinua (grupo M1) que es compatible con la existencia de un posible foso orientado en dirección norte-sur, paralelo al pequeño curso que actualmente discurre algo más al oeste (Fig. 12); otra anomalía que presenta valores negativos (grupo M3) podría corresponder a los vestigios de una gran estructura constructiva o a un potente nivel de derrumbe. Estas anomalías son congruentes con el análisis del modelo digital del terreno a partir de datos LiDAR, que también indica una depresión longitudinal compatible con la presencia de un posible foso (Fig. 5). Por último, una anomalía circular (M7) presenta las características típicas de un dipolo magnético provocado por alteraciones térmicas, por lo que podría corresponder a los restos de un horno o un incendio.

Por el contrario, la zona explorada con georradar mostró una definición correcta y un alcance en pro- 


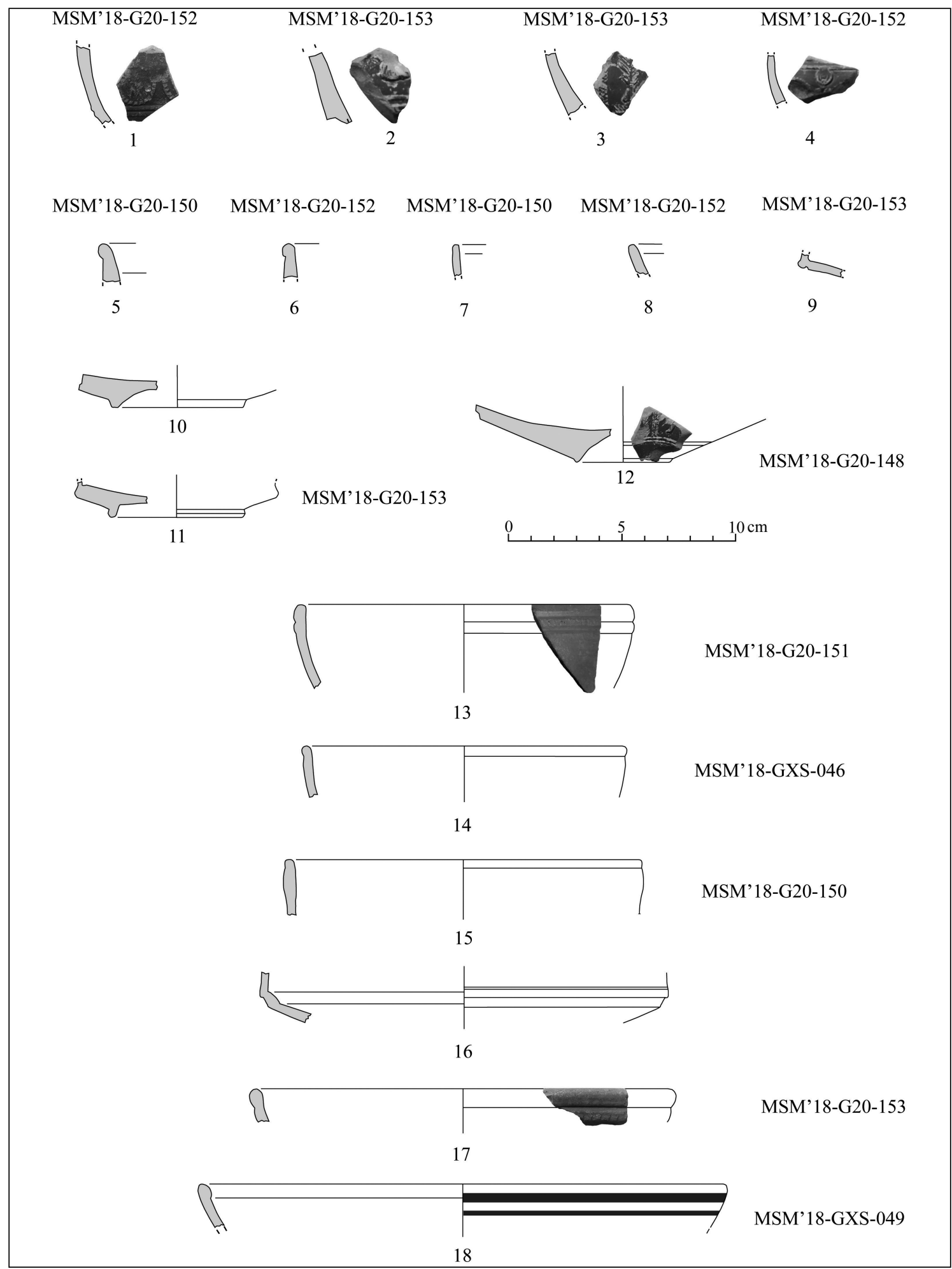

Figura 11. Vajilla romana. Sigillata aretina (9); Sigillata sudgálica (16); Sigillata Africana Clara A (11 y 17); cerámica de cocina africana (18). El resto son producciones hispánicas (elaboración propia). 


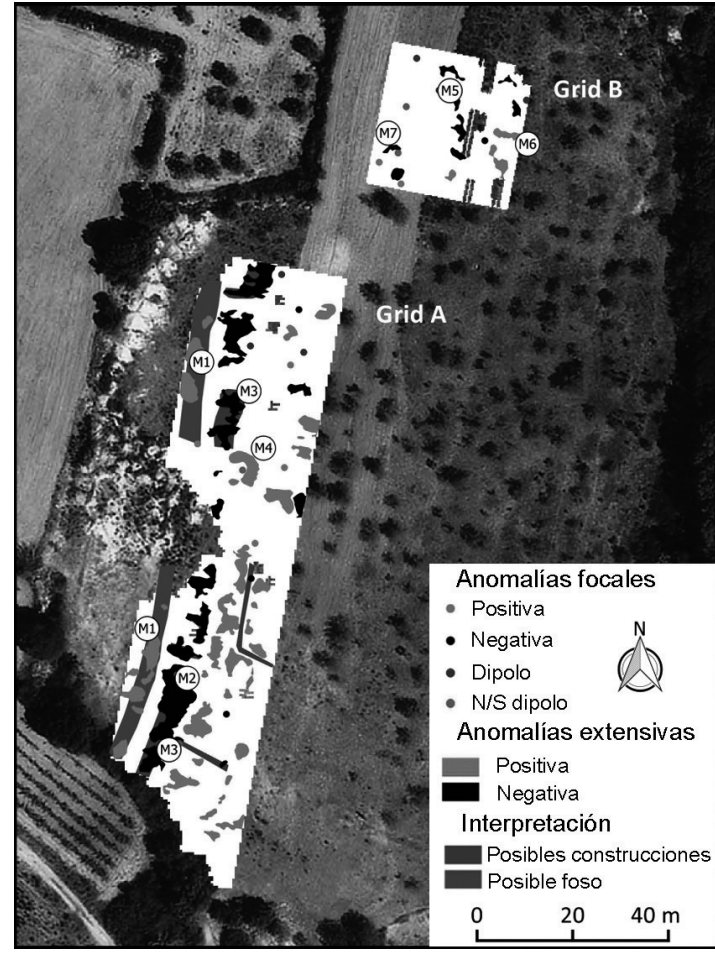

Figura 12. Resultados de la exploración magnética realizada en la parte occidental de la zona prospectada (elaboración propia).

fundidad de 1,5 m, suficiente para la obtención de datos coherentes sobre los restos constructivos. Se concluyó, por tanto, que esta última era el método más adecuado para completar la cobertura, en una superficie total de $14.875 \mathrm{~m}^{2}$. En general, se han obtenido datos fiables, a pesar de las dificultades derivadas de la irregularidad de la superficie y de las interrupciones en las lecturas causadas por la presencia de árboles de cultivo de secano, que han repercutido negativamente en la calidad de los resultados. En cuanto a la interpretación de los datos de georradar, de una secuencia de dieciocho cortes horizontales se han seleccionado los quince que se consideran representativos de los elementos detectados. Han permitido comprobar que el trazado urbano y, probablemente, la estructura interna de los bloques constructivos son los mismos desde el corte inferior (-1,46 a -1,30 m) hasta el de $-0,65$ a $0,49 \mathrm{~m}$. Tan solo en este último se aprecian estructuras que aparentemente interrumpen algunas vías de paso, pero su interpretación no es evidente. Los resultados se han analizado conjuntamente por los arqueólogos y geofísicos del equipo de trabajo para producir plantas de trazos vectoriales (Fig. 13), a partir de las cuales se ha elaborado una planta hipotética (Fig. 14).

\section{INTERPRETACIÓN ARQUEOLÓGICA DE LOS RESULTADOS DE LA PROSPECCIÓN GEOFÍSICA}

La observación de las plantas obtenidas muestra a simple vista la destrucción de la parte oriental del yacimiento, debida a la acción erosiva del torrente de Sant Miquel. La superficie desaparecida puede estimarse en unos $10 \mathrm{~m}$ de longitud en dirección esteoeste de media, afectando probablemente a la totalidad de esta parte oriental (Fig. 15).

Se observa que el asentamiento estaba protegido por una muralla cuyo grosor medio puede evaluarse en unos 2 m, aproximadamente (Fig. 14, 1). Es reconocible en la parte occidental, donde presenta un trazado ligeramente sinuoso sobre una longitud de unos $140 \mathrm{~m}$, y también en el lado meridional, en este caso sobre una longitud conservada algo superior a los 70 $\mathrm{m}$, aunque originalmente pudo rebasar los $90 \mathrm{~m}$. Con toda evidencia, el primero de estos tramos se prolongaba hacia el norte y nordeste para enlazar, probablemente, con el sector de fortificación descubierto en el sondeo de urgencia de 1998, y sin duda aún más allá para proteger toda la parte septentrional del asentamiento, la más vulnerable. No es posible determinar, con los datos actuales, si existía también un lienzo oriental, dada la destrucción, ya mencionada, de esta parte del yacimiento; no puede excluirse, aunque también es posible que el curso del torrente de Sant Miquel -un obstáculo considerable- se considerara suficiente para asegurar la defensa.

Hay indicios de la existencia de tres construcciones cuadrangulares aparentemente relacionadas con esta muralla y que podrían corresponder a otras tantas torres. La primera (T1) se encuentra en la parte noroccidental; se trata de tres grandes fragmentos de muro, dos de los cuales forman ángulo recto; se opone, sin embargo, a la idea de que se trate de los restos de una torre el hecho de que aparentemente no conecten con la muralla. De haber existido realmente, las dimensiones de esta torre (T1) serían de unos $14 \times 6$ m aproximadamente. Más evidente parece la existencia de dos torres en el lienzo meridional. Una de ellas, de planta aproximadamente cuadrada (unos $6 \times 6 \mathrm{~m}$ ), se encuentra junto al ángulo sudoccidental (T2), mientras que la segunda (T3), de planta rectangular alargada (unos $15 \times 4 \mathrm{~m}$ ), se halla en el extremo oriental de la zona prospectada. La única puerta de acceso reconocible se encuentra en la parte central del lienzo meridional, coincidiendo con el extremo sur de la calle principal del asentamiento.

En la parte occidental y, menos claramente, en la meridional, se reconocen los restos de un segundo muro (2), documentado de manera discontinua, en 


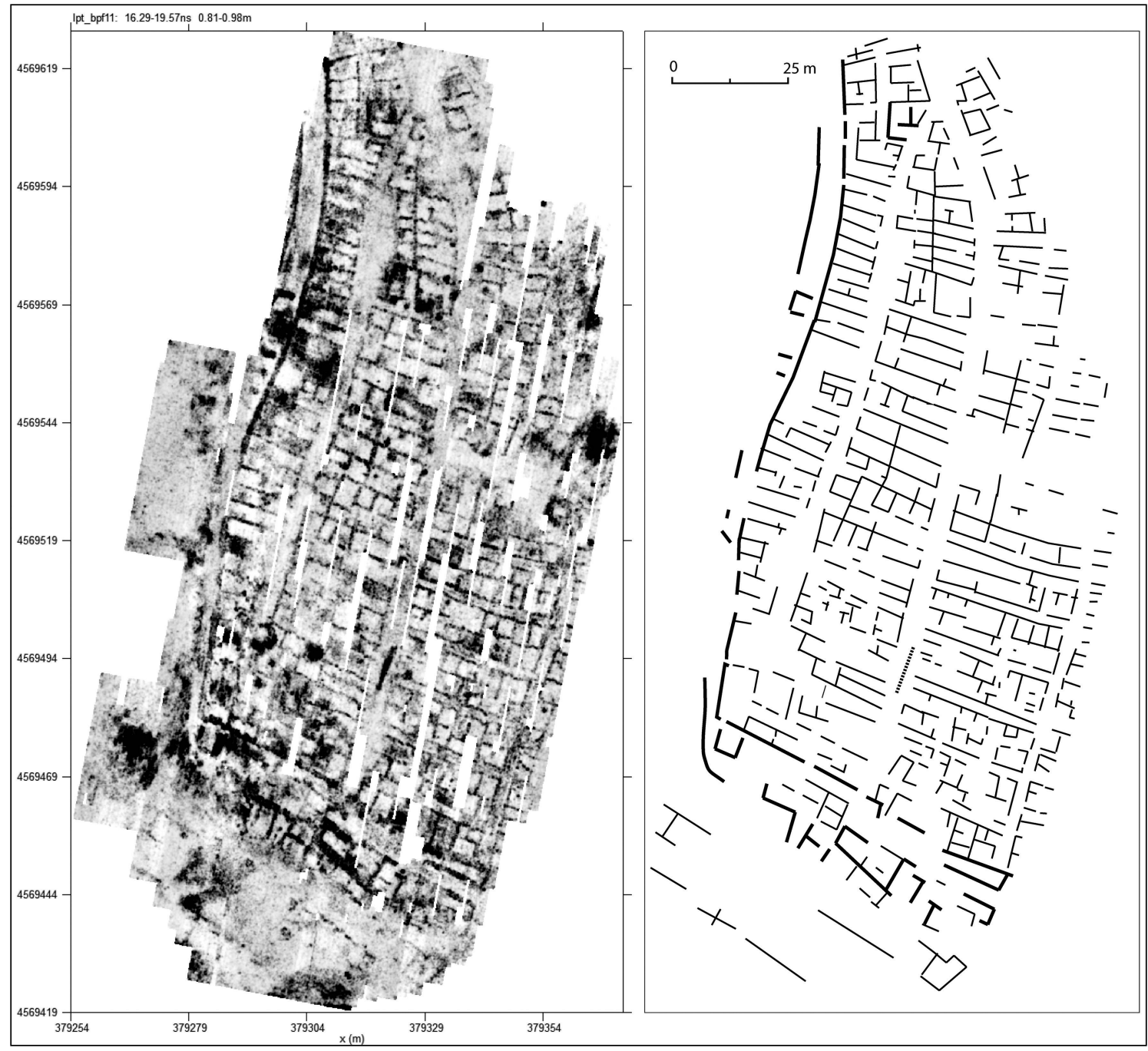

Figura 13. Imagen de la prospección con georradar en el corte horizontal situado entre los 0,81 y los 0,98 metros de profundidad, y plasmación de las anomalías en una planta vectorial (elaboración propia).

parte, sin duda, por la existencia de un bancal que impidió el acceso de los aparatos de prospección geofísica. Se han documentado tres tramos de distinta longitud, situados a una distancia que varía entre un mínimo de unos $3 \mathrm{~m}$ (los dos que se encuentran inmediatamente al oeste) y un máximo de unos $11 \mathrm{~m}$ cerca de ángulo sudoeste, al sur de T2. Siguen un trazado básicamente paralelo al de la muralla, de lo que se deduce que se trata de una obra de fortificación. Puede excluirse la posibilidad de que sea el muro de escarpa de un foso, dado que las cotas superiores de estos muros coinciden aproximadamente con las de la muralla; además, están excesivamente alejados (entre 10 y $12 \mathrm{~m}$ ) de las anomalías interpretadas como un posible foso. Dado que el muro exterior se antepone a las torres antes mencionadas, es preciso suponer que se levantó en una segunda fase, creando de esta manera un largo corredor de acceso (de una longitud mínima de $46 \mathrm{~m}$ ) a una puerta, desconocida por el momento, que se abriría en la muralla interna. Es probable que las torres se conservaran con objeto de dificultar el paso por este corredor. Los paralelos más próximos de una disposición de este tipo se encuentran en Kerkouane y en Lilibeo. En el primero de estos yacimientos resulta de una larga evolución que culminó en el siglo III a. C. (Fantar 2012: 13-14 y fig. 1). También en el caso de Lilibeo, el muro exterior se levantó en el siglo III a. C., a unos $10 \mathrm{~m}$ por delante de la antigua muralla (Caruso 2006: 279 y fig. 93). Es plausible que la reestructuración de las defensas de 


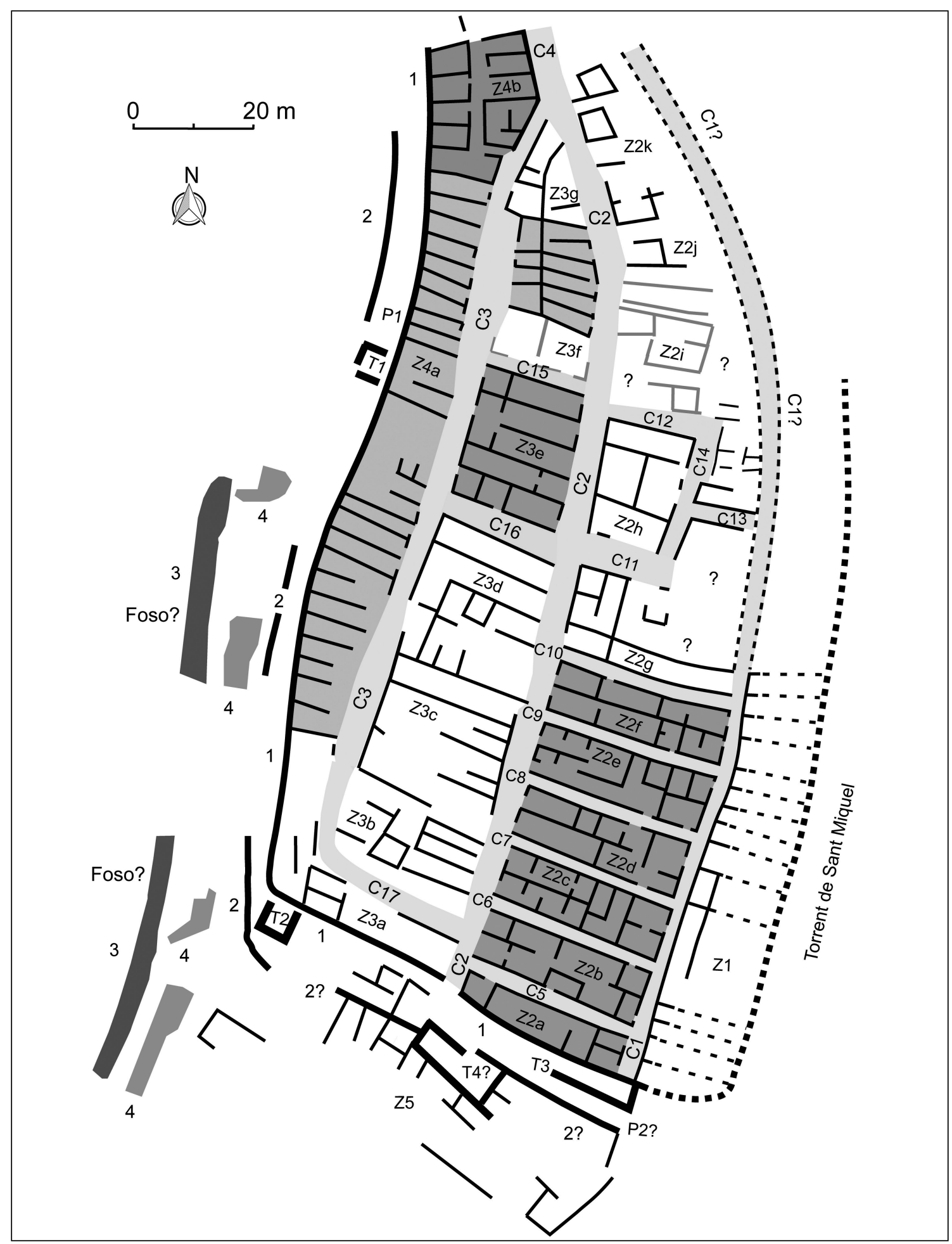

Figura 14. Planta interpretada de los resultados de la prospección geofísica. En trama gris, los espacios de circulación. En línea gris, bloques constructivos no completamente delimitados por calles. En línea negra discontinua, trazado hipotético de la zona desaparecida por la erosión (elaboración propia). 


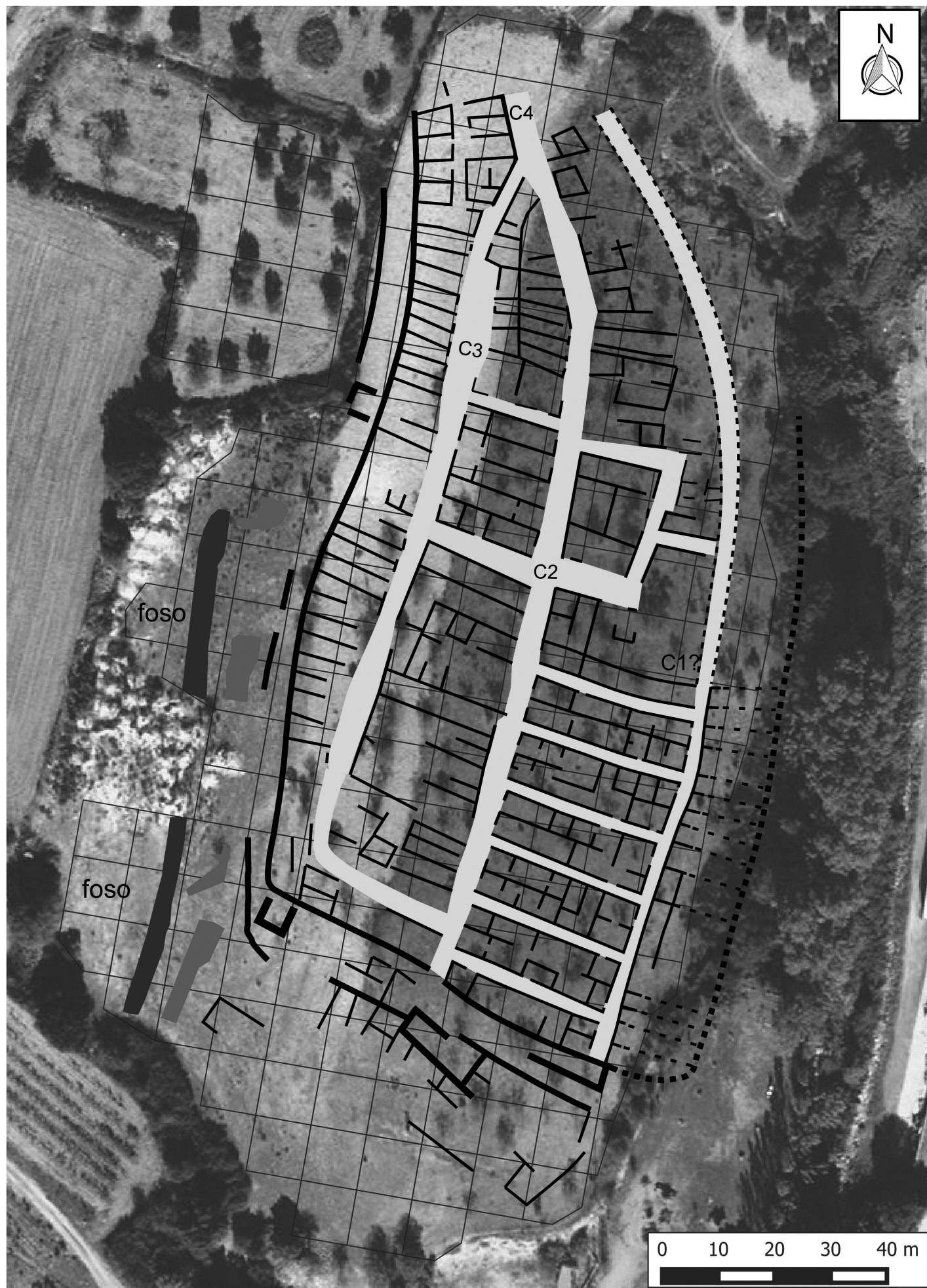

Figura 15. Imagen compuesta con indicación de la cuadrícula de prospección y la trama urbana hipotética sobre ortofotografía (base Institut Cartogràfic i Geogràfic de Catalunya) (elaboración propia). 
Masies de Sant Miquel date de este mismo momento, es decir, de la última etapa de la vida de la ciudad, y que tal vez tenga alguna relación con la política de preparación de la segunda guerra púnica por parte de los bárquidas, que hemos defendido en otras ocasiones (Sanmartí et alii 2012).

En la parte meridional, la restitución hipotética de esta posible primera muralla es más complicada, debido a la existencia de un gran número de muros (agrupados bajo la denominación de Z5) que, sin embargo, no presentan una estructura coherente; la existencia de un gran edificio turriforme (¿T4?) sería consecuente con la posible extensión del muro exterior en esta parte del yacimiento. Podría asimismo plantearse la posibilidad de que existiera una puerta en corredor (¿P2?) en la parte sudoriental. Sea como fuere, la existencia de este importante conjunto de estructuras extramuros indica que el yacimiento experimentó momentos de crecimiento o de retracción a lo largo de su historia.

La prospección magnética también indica, como se ha dicho, la posible existencia de un foso en el límite suroccidental del asentamiento (3); su trayectoria es paralela a la de la muralla, pero se extiende hacia el sur hasta por lo menos treinta metros más allá del sector meridional de la misma, donde gira aparentemente hacia el este para enlazar con el barranco de Sant Miquel. La misma prospección sugiere también la probable existencia de otro muro de gran espesor (4) entre la muralla exterior antes mencionada (2) y el posible foso. Al igual que este último, también se extiende hacia el sur más allá de del lienzo meridional de la muralla. No puede excluirse que se trate de la escarpa del foso.

En definitiva, parece haber existido un sistema defensivo de notable complejidad estructural, lo que sin duda se explica por la escasa protección proporcionada por las condiciones naturales del terreno, pero también por la importancia del lugar en el sistema de poblamiento cesetano. Con todo, su aparente complejidad puede resultar en parte de la existencia de estructuras de cronología diversa, que no funcionaron en realidad conjuntamente. Solo los trabajos de excavación permitirán confirmarlo.

En cuanto a la estructura viaria de la zona prospectada, se basa fundamentalmente en tres calles principales, de una anchura variable, orientadas en dirección norte-sur (calles 1 a 3). La más oriental (C1) mide unos 2,50 $\mathrm{m}$ de anchura media, y solo puede seguirse claramente en una longitud de unos 70 m; más al norte su trazado se desdibuja por completo, aunque es posible proponer una restitución teórica del mismo a partir de los restos de construcciones que se documentan hacia el noroeste y por analogía con la calle 2 (C2), situada inmediatamente al oeste. Esta última sigue aproximadamente el eje longitudinal del asentamiento y tiene una anchura media de unos $4 \mathrm{~m}$. En su extremo norte gira ligeramente hacia el noroeste para confluir con la calle 3 (C3). La continuación de ambas hacia el noroeste se ha denominado calle 4 (C4). Se trata aparentemente de una vía de anchura notable, unos $5 \mathrm{~m}$, y no puede excluirse que existiera en este punto un espacio abierto de dimensiones aún mayores, aunque los datos disponibles impiden afirmarlo de manera taxativa.

Las tres vías mencionadas separan cuatro grandes zonas de habitación, cada una de ellas con unas características singulares. La más oriental (Z1) está prácticamente destruida debido a la acción erosiva del torrente de Sant Miquel. Se distingue, sin embargo, una parte importante de las fachadas que delimitan por el este la calle 1, así como el arranque de una serie de muros perpendiculares a las mismas por el lado oriental, cuya longitud conservada no supera en ningún caso los $4 \mathrm{~m}$, y que permiten reconocer la existencia de un mínimo de 15 recintos (aunque algunos podrían ser vías de paso). Con estos datos, resulta imposible formular ninguna hipótesis sólida sobre la estructura de estas construcciones. Es perfectamente posible que se trate de edificios compuestos por un solo recinto rectangular alargado, o tal vez por dos, como los que se documentan (según se verá más adelante) adosados al lienzo occidental de la muralla. Con todo, la identificación de un largo muro transversal paralelo a las fachadas podría indicar la existencia de algún edificio de mayores dimensiones y de estructura más compleja.

Inmediatamente al oeste de la calle 1, entre esta y la calle 2, existe una segunda zona de construcciones (Z2), dividida transversalmente por una serie de calles estrechas (C5 a C11), cuya anchura media puede evaluarse en unos $2 \mathrm{~m}$, excepto en el caso de C11, que podría medir unos $5 \mathrm{~m}$. Estas vías delimitan una serie de bloques de forma rectangular alargada, seis más concretamente (Z2a a Z2f), orientados aproximadamente en dirección este-oeste, cuyas dimensiones medias pueden cifrarse en unos $30 \mathrm{~m}$ de longitud por unos $9 \mathrm{~m}$ de anchura (tal vez 100 por 30 pies $^{13}$ ). El bloque más meridional (Z2a) tiene una anchura ligeramente inferior, debido sin duda a la presencia de la muralla. Al norte de la calle C10, la estructura descrita se desdibuja. El bloque Z2g es aparentemente de mayor anchura (unos 14 m); aún más allá, puede proponerse la existencia de un bloque (Z2h) de forma ligeramente

\footnotetext{
13 Según la medida de $31,1 \mathrm{~cm}$ que propone Pau Olmos para un pie de creación original ibérica, cuya utilización se documenta en los asentamientos ibéricos de Cataluña entre el siglo V y III a. C. (Olmos 2010).
} 
trapezoidal, delimitado por las calles $\mathrm{C} 2, \mathrm{C} 14, \mathrm{C} 11 \mathrm{y}$ $\mathrm{C} 12$, con unas dimensiones aproximadas de unos $13 \mathrm{~m}$ por $20 \mathrm{~m}$. Inmediatamente al norte se ha agrupado bajo el nombre de Z2i una serie de construcciones que no parecen conformar una estructura coherente. Lo mismo puede decirse en relación con la zona que se extiende en dirección noroeste hasta la confluencia de las calles 2 y 3: la distinción entre los bloques Z2j y Z2k es en realidad arbitraria, y responde básicamente a la suposición de que existió dentro de este conjunto una vía de paso en dirección este-oeste.

En lo que se refiere a la estructura interna de los bloques que componen esta zona construida, no se reconoce claramente la existencia de un patrón constante, ni siquiera entre los situados en la parte meridional. Tampoco se distinguen con nitidez las distintas unidades funcionales, lo que en parte puede ser debido a la imposibilidad de discriminar muros correspondientes a distintas fases cronológicas, así como a las dificultades para identificar con seguridad las puertas de comunicación interna entre los distintos ámbitos. De todas formas, y con la mayor prudencia, parece observarse en los bloques Z2b a Z2f una tendencia general a la subdivisión según el eje longitudinal, con el que coinciden siempre varios muros, algunos de ellos de longitud considerable, tal vez incluso, en el caso de Z2f, de extremo a extremo del bloque. Por el contrario, no se distinguen claramente subdivisiones según el eje transversal, excepto, tal vez, en Z2c y Z2d. La notable superficie de estos bloques (unos $230 \mathrm{~m}^{2}$ ) permite suponer que contenían diversas casas, tal vez dos de unos $110 \mathrm{~m}^{2}$, como parece insinuarse en los bloques Z2c y Z2d. Sin embargo, los datos disponibles no permiten ir más allá, ni excluyen la posibilidad de que estuvieran ocupados por una sola residencia cada uno. Nada puede afirmarse en relación con $\mathrm{Z} 2 \mathrm{~g}$, mientras que los datos sobre la estructura interna de $\mathrm{Z} 2 \mathrm{~h}$ sugieren cuatro grandes recintos, probablemente divididos internamente; puede tratarse de una sola gran casa, de superficie igual a la de los bloques constructivos rectangulares situados más al sur $\left(230 \mathrm{~m}^{2}\right)$.

Una tercera zona construida (Z3) se encuentra entre la calle 2, al este, y la calle 3 , al oeste. Se distinguen dos vías transversales (C15 y C16). Inmediatamente al norte de $\mathrm{C} 15$ parecen existir dos grandes recintos de proporciones próximas al cuadrado, tal vez accesibles desde las tres calles adyacentes (Z3f). Aún más al norte hay un largo muro orientado en dirección norte-sur, que sirve de pared trasera común para dos series de recintos adosados (Z3g), abiertos respectivamente a las calles 2 y 3 . Es posible que cada uno de ellos constituya una casa individual, pero no pueden excluirse otras funciones, como el almacenaje.

Al sur de C15, hasta la muralla, el espacio parece haber sido dividido primariamente en unidades rectan- gulares de anchura más o menos equivalente (unos $4 \mathrm{~m}$ ) y una longitud que varía entre 17 y $20 \mathrm{~m}$, con una superficie media de unos $70 \mathrm{~m}^{2}$. Uno de ellos, C16, era la calle que prolonga $\mathrm{C} 11$ y que, junto con $\mathrm{C} 15$, delimita un bloque constructivo (Z3e) de unos $400 \mathrm{~m}^{2}$, compuestopor cinco de los espacios rectangulares mencionados. Podría tratase de una sola gran casa, aunque su estructura espacial no permite asegurarlo. El espacio construido al sur de C16 cubre unos $1300 \mathrm{~m}^{2}$. Creemos que debió de estar ocupado por varias casas, probablemente de grandes dimensiones, cuyos límites, sin embargo, no se pueden establecer con los datos disponibles. Es posible que cada una estuviera formada por dos o tres de los espacios rectangulares antes mencionados, con una estructura similar a la que se documenta en el siglo IV a. C. en el yacimiento de Alorda Park, a tan solo 9 $\mathrm{km}$ de distancia (Asensio et alii 2005c).

La zona construida 4 (Z4) ocupa el espacio comprendido entre $\mathrm{C} 3$ y el lienzo occidental de la muralla. En la mayor parte del mismo se observa la existencia de espacios rectangulares, de unos 3,5 $\mathrm{m}$ de anchura media, yuxtapuestos y adosados a la muralla (Z4a). Hay por lo menos 25 construcciones de este tipo, pero pudieron ser más, dada la presencia de algún espacio donde no se han podido reconocer estructuras organizadas coherentemente, sobre todo en el extremo meridional de esta zona. Tendemos a pensar que cada uno de estos recintos correspondía a un espacio independiente, pero no se puede excluir que existieran puertas internas de comunicación entre algunos de ellos, y que formaran de este modo estructuras algo más complejas, aunque sin duda, si así fuera, de entidad menor a las existentes en Z2 y Z3. La anchura relativamente reducida de estas construcciones debió de facilitar la existencia de una planta superior destinada a ejercer la función de paso de ronda, que implica la necesidad de soportar un peso importante por la presencia y circulación de los defensores. En el extremo septentrional de esta zona construida parece existir un gran edificio $\left(350 \mathrm{~m}^{2}\right)$, de estructura distinta (Z4b), con recintos distribuidos a uno y otro lado de un largo corredor orientado en dirección norte-sur, cuatro al este y cuatro al oeste, más otro espacio en la parte meridional. El corredor comunica con el exterior a través de sendas puertas abiertas a C3 y a un espacio situado inmediatamente al norte.

\section{CONCLUSIONES}

La extensión e importancia de Masies de Sant Miquel con anterioridad al siglo III a. C. no puede determinarse con seguridad, pero la existencia en su entorno inmediato de una necrópolis del período ibérico antiguo sugiere que ya en ese momento se trataba de 
un núcleo de una cierta importancia. En efecto, como hemos señalado en otros trabajos (Sanmartí et alii 2015), durante el período ibérico, y al norte de la gran concentración de yacimientos funerarios de la zona del Ebro, la presencia de necrópolis se asocia generalmente (aunque existan algunas tumbas aisladas, como la de Granja Soley) (Sanmartí Grego et alii 1982) a núcleos de población importantes, como Ullastret, Burriac, Sant Julià de Ramis o el yacimiento que ahora nos ocupa. Ello se explica verosímilmente por el desarrollo de un código cognitivo compartido en que se atribuía al sector social dominante una naturaleza particular, diferenciada de la del resto de la población, así como una relación especial con el mundo sobrenatural, tal vez fundamentada, por una parte, en una supuesta descendencia directa de antepasados distinguidos, y, por otra, en la creencia en formas particulares de persistencia en el mundo del más allá, diferentes de las de los otros miembros de la sociedad. En definitiva, se trataría de la aparición de una ideología legitimadora de la desigualdad, que, de manera inevitable, debió de acompañar la formación de las sociedades complejas y el surgimiento de las primeras ciudades de la zona.

Sin duda, la imagen que se obtiene de nuestros trabajos de prospección corresponde, en lo esencial, al aspecto que tenía el asentamiento en su última fase de ocupación, en el siglo III a. C. En este momento, cubría una superficie de unas 3,5 ha y presentaba todas las características propias de una ciudad, tal como esta se ha definido en la introducción a este artículo. Se trata, en efecto, de un núcleo sólidamente fortificado, como cabía esperar de una población importante ubicada en llano, y se caracteriza por un urbanismo compacto, con ocupación total del espacio disponible, y una organización considerablemente regular, aunque no estrictamente ortogonal, de la red viaria. A pesar de las dificultades para individualizar los distintos edificios, parece evidente que existieron casas de dimensiones y de complejidad interna muy distintas, agrupadas en zonas construidas diferenciadas, lo que viene a coincidir con la información recuperada en otros asentamientos contemporáneos, como el Castellet de Banyoles (Tivissa) (Sanmartí et alii 2012) o Illa d'en Reixac (Ullastret) (Martín et alii 2004). Ello permite pensar en una notable diversidad social, y tal vez en la existencia de barrios ocupados por grupos gentilicios diferenciados, tal como hemos propuesto para el Castellet de Banyoles (Sanmartí et alii 2012).

Dadas las dificultades para identificar las unidades domésticas, es imposible proponer un cálculo de población basado en el número de casas. Moreno y Valor (2010) han calculado un índice de población de $26 \mathrm{~m}^{2}$ por habitante para la ciudad ibérica de Kelin. Si se aplicara a nuestro yacimiento, el resultado sería de unos mil habitantes (unas 200 a 250 familias), una cifra que, como hemos argumentado en otros trabajos (Belarte et alii 2019) y admiten también otros autores (Hansen 2008, 70, con referencias anteriores), se encuentra dentro de los límites de la población propios de las ciudades.

Las actividades económicas desarrolladas por esta población debieron de ser variadas, e incluyeron sin duda tanto la producción primaria como las actividades de transformación. Los datos disponibles no permiten precisarlas (excepto, posiblemente, el tejido, tal vez atestiguado por los restos de un ponderal) (Fig. 10: 24), pero la gran abundancia de ánforas y grandes envases de producción local o regional entre el material recuperado en recogida superficial sugiere una actividad importante ligada a la producción y almacenaje de alimentos envasados en dichos recipientes, que seguramente rebasa, y con mucho, las necesidades locales. Entre estos productos puede pensarse que tuvieron un papel importante las bebidas fermentadas.

La desaparición de este importante núcleo de poblamiento en los años en torno a $200 \mathrm{a}$. C. viene a confirmar la magnitud del impacto de la conquista romana en el nordeste de la península ibérica. El abandono en dicho momento de núcleos de primer orden como Ullastret o Burriac (aunque este último fuera reocupado más tarde), de otros de segundo nivel, pero importantes asimismo en la estructura del poblamiento, como Masies de Sant Miquel, el Vilar de Valls, Turó de ca n'Oliver o el Castellet de Banyoles de Tivissa, y de otros muchos de menor tamaño, pero de evidente importancia para el control del territorio (Alorda Park, Puig Castellar de Santa Coloma de Gramenet, Castellruf, Coll del Moro de Gandesa) y la explotación del mismo (Mas Castellar de Pontós, Turó del Vent, Turó de la Font de la Canya, etc.), son un síntoma evidente de cambios muy rápidos y profundos. En el mismo sentido debe interpretarse la interrupción del uso de la necrópolis de Burriac. Todo ello indica claramente que la conquista romana supuso la decapitación de la sociedad ibérica de la zona en cuestión.

\section{BIBLIOGRAFÍA}

Adserias, M., Cela, X. y Marí, L. 2000-2001: “El poblat ibèric fortificat de Masies de Sant Miquel (Banyeres del Penedès, Tarragona)", Revista d'Arqueologia de Ponent 11-12, 255-275.

Alaminos, A., Ojuel, M. Sanmartí, J. y Santacana, J. 1991: "Algunas observaciones sobre el comercio colonial en la costa central y meridional de Cata- 
lunya en época arcaica", J. Remesal y O. Musso (eds.), La presencia de material etrusco en la Península Ibérica, Barcelona, 275-294.

Asensio, D. 2004: "Cerámicas de cocina cartaginesas en contextos ibéricos de la costa catalana", G. Mantilla, A. Egea y A. González (eds.); El mundo púnico: religión, antropologia y cultura material, Actes del II Congreso Internacional de Mundo Púnico, Estudios Orientales 5-6, 305-318.

Asensio, D. 2015: “Ceràmiques importades, béns de prestigi, practiques socials i sistemes productius entre les comunitats ibèriques del nord-est peninsular", M. C. Belarte, D. Garcia y J. Sanmartí (eds.), Les estructures socials protohistòriques a la Gàl-lia i a Ibèria. Homenatge a Aurora Martín i Enriqueta Pons. Actes de la VII Reunió Internacional d'Arqueologia de Calafell (Calafell, del 7 al 9 de març de 2013), Arqueo Mediterrània 14, Barcelona, 237-249.

Asensio, D., Cela, X. y Morer, J. 2005a "El jaciment protohistòric el Turó de la Font de la Canya (Avinyonet del Penedès, Alt Penedès): un nucli d'acumulació d'excedents agrícoles a la Cossetània (segles VII-III aC)", Fonaments: Prehistòria $i$ Món Antic als Països Catalans 12, 123-126.

Asensio, D., Jornet, R., López Reyes, D. y Morer de Llorens, J. 2005b: "La troballa d'una màscara grotesca de terra cuita en el jaciment ibèric de Mas d'en Gual (el Vendrell, Baix Penedès)", Fonaments: Prehistòria i Món Antic als Països Catalans 12, 223-233.

Asensio, D., Morer, J., Sanmartí, J., Santacana, J. y Pou, J. 2005c: "Evidències arqueològiques del procés d'emergència d'élites aristocràtiques a la ciutadella ibèrica d'Alorda Park (Calafell, Baix Penedès)", O. Mercadal (ed.), Món ibèric : als Països Catalans: XIII Col-loqui Internacional d'Arqueologia de Puigcerdà: homenatge a Josep Barberà i Farràs: Puigcerdà, 14 i 15 de novembre de 2003, 597-614.

Bea, D. 1996: "La necròpolis de Can Canyís. I. El material ceràmic", Butlletí Arqueològic. Reial Societat Arqueològica Tarraconense 18, 23-37.

Bea, D., Carilla, A y Chimisanas, E. 1996: "La necròpoli de Can Canyís (Banyeres del Penedès, Baix Penedès): una revisió del material funerari”, Miscel-lània Penedesenca 21, 35-52.

Belarte, M. C., Noguera, J., Plana, J. y Sanmartí, J. 2019: "On the notion of the city and its relevance for the study of the western Mediterranean Protohistory”, M. C. Belarte, J. Noguera R. Plana y J. Sanmartí (eds.), Urbanization in Iberia and Mediterranean Gaul in the first millennium BC, TRAMA 7, Tarragona, 11-18.
Carrasco, P., Pallejà, L. y Revilla, V. 1995: "Excavaciones en el poblado ibérico de les Masies de Sant Miquel (Banyeres del Penedès, Baix Penedès)", Butlletí Arqueològic. Reial Societat Arqueològica Tarraconense 17, 5-35.

Caruso, E. 2006: "Le fortificazioni di Lilibeo: un monumentale esempio della poliorcetica punica in Sicilia”, C. Ampolo (ed.), Guerra e pace in Sicilia e nel Mediterraneo antico (VIII-III sec. a.C.) Arte, prassi e teoria della pace e della guerra, vol. I, Pisa, 283-305.

Cela, X., Adserias, M. y Revilla, V. 2001: "El oppidum ibérico de Masies de Sant Miquel (Banyeres del Penedès)", J. Guitart, J. M. Palet y M. Prevosti (coords.), Territoris antics a la Mediterrània i a la Cossetània oriental. Actes del Simposi Internacional d'Arqueologia del Baix Penedès, Barcelona, 255-264.

Codina, F., Garcia-Garcia, E., Martín, A., De Prado, G., Sala, R. y Tamba, R. 2016: "Combined results, interpretation and conclusions of all the systems", E. Garcia-Garcia, G. De Prado y J. Principal (eds.), Working with buried remains at Ullastret (Catalonia). Proceedings of the $1^{\text {st }}$ MAC International Workshop of Archaeological Geophysics, Monografies d'Ullastret 3, Girona, 97-110.

Fantar, M. 2012: "Les ouvrages de défense dans la cité punique de Kerkouane”, F. Déroche y J. Leclant (eds.), Enceintes urbaines, sites fortifiés, forteresses d'Afrique du Nord. Actes de la Ve Journée d'études nord-africaines, Paris, 9-23.

Ferrer, C., García, J., Morer, J. y Rigo, A. 2003: "Fondo del Roig (Cunit). Un nucli camperol ibèric de la Cossetània”, J. Guitart, J. M. Palet y M. Prevosti (coords.), Territoris antics a la Mediterrània i a la Cossetània oriental. Actes del Simposi Internacional d'Arqueologia del Baix Penedès, Barcelona, 339-348.

Ferrer, A. y Giró, P. 1943: La colección prehistórica del Museo de Vilafranca del Panadés, Barcelona.

Hansen, M. H. 2008: "Analyzing cities", J. Marcus y J. A. Sabloff (eds.), The Ancient city: new perspectives on urbanism in the old and new world, Santa Fe NM, 67-76.

Martín, A., Casas, S., Codina, F., Margall, J. y De Prado, G. 2004: "La zona 14 de l'oppidum del Puig de Sant Andreu d'Ullastret. Un edifici dels segles IV i III aC", Cypsela 15, 265-284.

Morel, J.-P. 1994: "La céramique attique à vernis noir en Ibérie et à Carthage: une comparaison”, E. Sanmartí, R. Olmos y P. Cabrera (eds.), Iberos y griegos: lecturas desde la diversidad, Huelva Arqueológica XIII, 2, 323-344. 
Moreno, A. y Valor, J. 2010: “Casas, Personas y Comunidades: aproximación al cómputo poblacional de la ciudad ibérica de Kelin (Caudete de las Fuentes, València) y su territorio", Arqueología Espacial 28 Arqueología de la Población, Teruel, 245-264.

Munilla, G. 1991: "Elementos de influencia etrusca en los ajuares de las necrópolis ibéricas”, J. Remesal y O. Musso (eds.), La presencia de material etrusco en la Península Ibérica, Barcelona, 107-175.

Olmos, P. 2010: Estudi dels patrons mètrics, arquitectònics $i$ urbanístics del món ibèric $(S . V-I I a C)$, Tesis doctoral, Universitat Rovira i Virgili, Tarragona. http://www.tdx.cat/handle/10803/8641

Padró, J. 1971: "Breus notes sobre els escarabeus i escaraboids de la necròpolis de Can Canyís", Pyrenae 7, 129-133.

Padró, J. 1980: Egyptian-type documents: from the Mediterranean littoral of the Iberian Peninsula before the Roman conquest, Leiden.

Principal, J. 1998: Las importaciones de vajilla fina de barniz negro en la Cataluña sur y occidental. Comercio y dinámica de adquisición en las sociedades indígenas, BAR International Series 729.

Revilla, V. 2014: “Contextos cerámicos de época altoimperial de la villa del Vilarenc (Calafell, Tarragona)", M. Roca, M. Madrid y R. Celis (eds.), Contextos ceràmics d'època altimperial a la Mediterrània occidental, Barcelona, 123-149.

Sala, R., Garcia, E. y Tamba, R. 2012: “Archaeological Geophysics. From Basics to New Perspectives", I. Ollich, (ed.), Archaeology, New Approaches in Theory and Techniques, 133-166. https://doi. org/10.5772/45619

Sala, R., Principal, J., Olmos, P., Tamba, R. y Garcia, E. 2013: "Multimethod Geophysical Survey at the Iron Age Iberian Site of El Molí d'Espígol (Tornabous, Lleida, Catalonia): Exploring Urban Mesh Patterns Using Geophysics", Archaeological Prospection 20 (4), 249-265. https://doi.org/10.1002/ arp. 1459

Sala, R., Tamba, R. y Garcia, E. 2016: "Application of Geophysical Methods to Cultural Heritage", Elements 12 -1, 19-25. https://doi.org/10.2113/gselements.12.1.19

Sanmartí, J. 2000: "Les importations de céramique attique du $\mathrm{IV}^{\mathrm{e}}$ s. av. J.-C. sur la côte centrale de Catalogne", B. Sabatini (ed.), La céramique attique du IVe siècle en Méditerranée occidentale. Actes du colloque international organisé par le Centre Camille Jullian, Collection de Centre Jean Bérard, 19; Travaux du Centre Camille Jullian, 24, Nápoles, 233-241.

Sanmartí, J. 2014: "Long-term social change in Iron Age northern Iberia”, B. A. Knapp y P. Van Dommelen (eds.), The Cambridge Prehistory of the Bronze \& Iron Age Mediterranean, Nueva York, 454-470. https://doi.org/10.1017/cho9781139028387.033

Sanmartí, J. 2015: "Interactions coloniales, cuisine et formes de consommation en Ibérie septentrionale", R. Roure (ed.), Contacts et acculturations en Méditerranée occidentale. Hommages à Michel Bats, Bibliothèque d'Archéologie Méditerranéenne et Africaine, 15, 171-183.

Sanmartí, J. y Asensio, D. 2005: “Comercio púnico y estratificación social: la difusión de cerámicas comunes en la costa nordoriental de la Península Ibérica", V Congresso Internazionale di Studi Fenici e Punici (Marsala-Palermo, 2-8 ottobre 2000), Palermo, 1299-1310.

Sanmartí, J., Asensio, D. y Martín, A. 2002: “Les relacions comercials amb el món mediterrani dels pobles indígenes de la Catalunya sudpirinenca durant el periode tardoarcaic (ca. 575-450 aC)", Cypsela, 14, 69-106.

Sanmartí, J., Asensio, D., Miró, M. T. y Jornet, R. 2012: "Castellet de Banyoles (Tivissa): Una ciudad ibérica en el curso inferior del río Ebro", Archivo Español de Arqueología 85, 23-43. https://doi. org/10.3989/aespa.085.012.003

Sanmartí, J., Belarte, M. C., Noguera, J., Asensio, D., Jornet, R. y Morer, J. 2019: “A city-state system in the pre-roman Mediterranean West: the Iberian cities of eastern Catalonia", M. C. Belarte, J. Noguera, R. Plana y J. Sanmartí (eds.), Urbanization in Iberia and Mediterranean Gaul in the first millennium BC, TRAMA 7, Tarragona, 91-108.

Sanmartí, J., Bruguera, R. y Morer, J. 1998: "Les àmfores ibèriques de la Catalunya meridional", Quaderns de Prehistòria i Arqueologia de Castelló 19, 267-289.

Sanmartí, J., Plana, R. y Martín, A. 2015: “Les estructures socials en els estats ibèrics de la costa de Catalunya", M. C. Belarte, D. Garcia y J. Sanmartí (eds.), Les estructures socials protohistòriques a la Gàl-lia i a Ibèria. Homenatge a Aurora Martin i Enriqueta Pons. Actes de la VII Reunió Internacional d'Arqueologia de Calafell (Calafell, del 7 al 9 de març de 2013), Arqueo Mediterrània 14, Barcelona, 119-136.

Sanmartí, J. y Santacana, J. 1992: El poblat ibèric d'Alorda Park, Calafell, Baix Penedès. Campanyes 1983-1988, Excavacions Arqueològiques a Catalunya, 11, Barcelona.

Sanmartí Grego, E. 1978a: La cerámica campaniense de Emporion y Rhode, Monografies Emporitanes IV, Barcelona.

Sanmartí Grego, E. 1978b: "L'atelier des patères des trois palmettes radiales et quelques productions 
connexes", Journées d'études de Montpellier sur la céramique campanienne, Archéologie en Languedoc, 1, 21-36

Sanmartí Grego, E., Barberà, J., Costa, F. y Garcia, P. 1982: "Les troballes funeràries d'època ibèrica arcaica de la Granja Soley (Santa Perpetua de Mogoda, Vallès Occidental, Barcelona)", Empúries 44, 71-103.

Solé Caralt, J. 1948: Bisbal histórica. Resumen histórico del Penedès, Tarragona.
Solé Caralt, J. 1952: "Inventario Nacional de folios arqueológicos", Noticiario Arqueológico Hispánico, 1, 173-251.

Vilaseca, S., Solé, J. M. a y Mañé, R. 1963: “La necrópolis de Can Canyís (Banyeres, Prov. de Tarragona)", Trabajos de Prehistoria VIII.

Recibido: 07-05-2019

Aceptado: 30-09-2019 